\title{
The Role of Stress-Responsive Transcription Factors in Modulating Abiotic Stress Tolerance in Plants
}

\author{
Youngdae Yoon ${ }^{1}$, Deok Hyun Seo ${ }^{2}$, Hoyoon Shin ${ }^{2}$, Hui Jin Kim ${ }^{2}$, Chul Min Kim ${ }^{3}$ \\ and Geupil Jang ${ }^{2, *}$ \\ 1 Department of Environmental Health Science, Konkuk University, Seoul 05029, Korea; yyoon21@gmail.com \\ 2 School of Biological Sciences and Technology, Chonnam National University, Gwangju 61186, Korea; \\ 198478@jnu.ac.kr (D.H.S.); loeline@naver.com (H.S.); gmlwls8747@naver.com (H.J.K.) \\ 3 Division of Horticulture Industry, Wonkwang University, Iksan 54538, Korea; chulmin21@wku.ac.kr \\ * Correspondence: yk3@chonnam.ac.kr
}

Received: 19 May 2020; Accepted: 29 May 2020; Published: 1 June 2020

\begin{abstract}
Abiotic stresses, such as drought, high temperature, and salinity, affect plant growth and productivity. Furthermore, global climate change may increase the frequency and severity of abiotic stresses, suggesting that development of varieties with improved stress tolerance is critical for future sustainable crop production. Improving stress tolerance requires a detailed understanding of the hormone signaling and transcriptional pathways involved in stress responses. Abscisic acid (ABA) and jasmonic acid (JA) are key stress-response hormones in plants, and some stress-responsive transcription factors such as ABFs and MYCs function as direct components of ABA and JA signaling, playing a pivotal role in plant tolerance to abiotic stress. In addition, extensive studies have identified other stress-responsive transcription factors belonging to the NAC, AP2/ERF, MYB, and WRKY families that mediate plant response and tolerance to abiotic stress. These suggest that transcriptional regulation of stress-responsive genes is an essential step to determine the mechanisms underlying plant stress responses and tolerance to abiotic stress, and that these transcription factors may be important targets for development of crops with enhanced abiotic stress tolerance. In this review, we briefly describe the mechanisms underlying plant abiotic stress responses, focusing on ABA and JA metabolism and signaling pathways. We then summarize the diverse array of transcription factors involved in plant responses to abiotic stress, while noting their potential applications for improvement of stress tolerance.
\end{abstract}

Keywords: Abiotic stress; tolerance; Transcription factor; Abscisic acid; Jasmonic acid

\section{Introduction}

Stress-responsive transcription factors play essential roles in abiotic stress responses and stress tolerance [1,2]. Therefore, these stress-responsive transcription factors may be important targets for developing crops with enhanced abiotic stress tolerance [3]. Plant stress hormones, such as abscisic acid (ABA) and jasmonic acid (JA), regulate plant abiotic stress responses [4,5]. ABA signaling pathways activate target transcription factors, such as the basic leucine zipper (bZIP) ABA-responsive element binding factor (ABF) transcription factors, and JA signaling pathways activate the basic helix-loop-helix (bHLH) MYC transcription factors. These transcription factors control ABA- and JA-dependent expression of stress-responsive genes, as demonstrated using knock-out and overexpression systems [6-8]. In addition, experimental and computational approaches have identified other stress-responsive transcription factors belonging to the NAC, AP2/ERF, MYB, and WRKY families, which are not direct components of ABA and JA signaling pathways but are essential for plant abiotic stress responses. In this review, we describe the roles of ABA and JA metabolism and signaling 
pathways, and of ABA and JA signaling-specific bZIP and bHLH transcription factors in plant abiotic stress responses. We also summarize other stress-responsive transcription factor families, such as NAC, AP2/ERF, MYB, and WRKY, which are involved in abiotic stress tolerance, and discuss studies using these transcription factors to improve abiotic stress tolerance in plants.

\section{ABA Signaling and ABF Transcription Factors}

\subsection{ABA Metabolism}

The key stress hormone ABA mediates plant responses to abiotic stress. For example, ABA mediates stress-induced modulation of plant development, such as root growth inhibition, leaf senescence, and stomatal closure $[9,10]$. ABA is biosynthesized through the enzymatic activity of 9-cis-epoxycartotenoid dioxygenase (NCED), abscisic aldehyde oxidase (AAO), cytosolic short-chain dehydrogenase/reductase (SDR), and MOLYBDENUM COFACTOR SULFURASE (MCSU), which mediate the production of xanthoxin, an ABA precursor, and the conversion of xanthoxin to ABA [11,12]. Abiotic stress promotes ABA biosynthesis [13]. Mass transcription of the genes encoding the key ABA biosynthetic enzymes is largely responsible for ABA production in response to abiotic stresses such as drought and osmosis, and many stress-responsive transcription factors, including members of the bZIP, MYC, NAC, AP2/ERF, and MYB families, are involved in the transcription of ABA biosynthesis genes [14-19]. ABA degradation also controls cellular ABA levels. The formation of ABA-glucose ester by UDP glucosyltransferase (UGT) is involved in ABA degradation, but ABA hydroxylation by cytochrome P450 monooxygenase 707A family members (CYP707As) appears to be largely responsible for ABA degradation [20]. Similar to the ABA biosynthetic genes, expression of CYP707As is regulated by abiotic stresses, such as drought, salinity, and oxidative stress. Moreover, knock-out or knock-down of CYP707As increase ABA levels, suggesting that CYP707A-mediated ABA degradation is an important process controlling cellular ABA levels [20-22]. The finding that ABA response and abiotic stress tolerance is altered in plants with knock-out or overexpression of ABA biosynthetic genes, including NCED, indicates that ABA metabolism is an essential step controlling plant abiotic stress responses [23]. Although ABA transport has not been fully elucidated, the results showing that ABA accumulates in roots and xylem sap in response to drought suggest that $A B A$ synthesized in roots is transported to shoots through xylems [24,25].

\subsection{ABA Signaling and $A B F$ Transcription Factors}

The ABA signaling pathway initiates with recognition of ABA by a complex including Pyrabactin Resistance 1 (PYR1)/PYR-Like (PYL)/Regulatory Component of ABA Receptor (RCAR) and signal transduction by Protein Phosphatase Type 2Cs (PP2Cs), and SNF1-Related Protein KINASES TYPE 2s (SnRK2s) [26]. These activate the ABA signaling-specific ABA-Responsive Element Binding Factor (ABF) transcription factors, which belong to a distinct subfamily of bZIP transcription factor, and regulate the expression of ABA-responsive genes, leading to the establishment of stress-specific transcription [27-29]. SnRK2s activate ABFs through direct phosphorylation. In the absence of ABA, PP2Cs inhibit the kinase activity of SnRK2s, thus blocking activation of the ABFs. When plants are exposed to abiotic stress, ABA biosynthesis is promoted, resulting in formation of the PYR/PYL-PP2C complex, which inhibits PP2C activity, thus activating SnRK2s to phosphorylate and activate ABFs [30] (Figure 1). The activated ABFs directly bind to the ABA-responsive element (ABRE), a major cis-element in ABA-responsive genes [31], and activate the transcription of other stress-responsive transcription factors, such as NACs and AP2/ERFs, which are also responsible for the expression of stress-responsive genes [32]. This transcriptional cascade changes the genome-wide transcription profile, inducing the plant defense system, to adapt to and survive the abiotic stress, suggesting that stress-responsive bZIPs, including $\mathrm{ABFs}$, are essential components of the plant response and tolerance to abiotic stress $[33,34]$. 


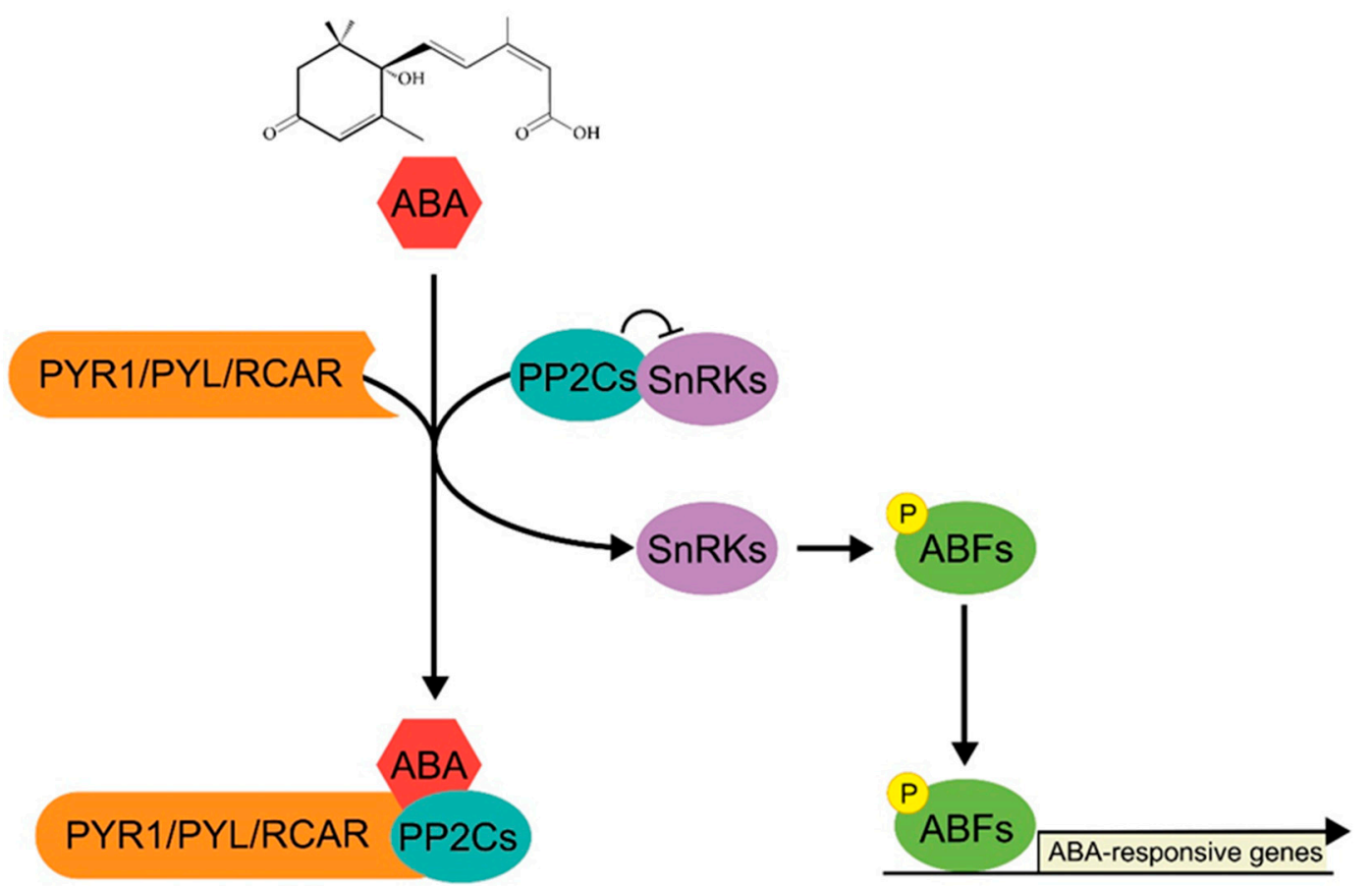

Figure 1. A schematic of ABA signaling pathway. In response to ABA, ABA receptor PYR1/PYL/RCAR forms a complex with PP2Cs, and activates SnRKs, the kinases that determine the activity of ABF transcription factors. SnRK-mediated phosphorylation of ABF promotes expression of ABA-responsive genes and $\mathrm{ABA}$ response.

The pivotal functions of $\mathrm{ABFs}$ in the $\mathrm{ABA}$ response and abiotic stress tolerance have been well documented in Arabidopsis thaliana. The transcription of $A B F 1,2,3$, and 4 is strongly upregulated by $\mathrm{ABA}$ or abiotic stress, and overexpression of $A B F 3$ and 4 promotes the expression of ABA-responsive genes, such ABA-INSENSITIVE 1 (ABI1) and ABI2, which encode PP2Cs, and whose mutations cause defects in ABA-dependent stomatal closure [35-37]. Furthermore, overexpression of $A B F 3$ and 4 significantly improves drought tolerance. For example, most wild-type plants withered by approximately 10 days of drought stress, whereas $A B F 3$ - and 4-overexpressing transgenic plants survived the drought stress [36]. In contrast to the $A B F 3$ - and 4-overexpressing plants, the abf2 abf3 abf4 triple mutant exhibited reduced drought tolerance compared to wild-type plants, and large-scale transcriptome analysis showed that expression of stress-responsive genes is impaired in the triple mutant [27]. These studies indicate that ABFs play an essential role in the plant response to abiotic stress. Moreover, $A B F 3$ and 4 are predominantly expressed in roots, suggesting that $A B F 3$ and 4 are involved in ABA response in roots [27,36]. Despite the functional redundancy of ABFs in ABA response and stress tolerance, it is likely that their functions do not completely overlap [36,38].

ABFs mediate stress-induced changes in plant development. For example, abiotic stress accelerates flowering and shortens the plant life cycle. A recent study by Hwang et al. revealed that $A B F 3$ and 4 regulate flowering time by controlling the expression of the floral integrator SUPPRESSOR OF OVEREXPRESSION OF CONSTANS 1 (SOC1) [38]. Mutant plants that lack expression of ABF3 and 4 exhibit reduced expression of $S O C 1$ and showed an ABA-insensitive late flowering phenotype, whereas transgenic plants ectopically expressing ABF3 or 4 displayed an early flowering phenotype. Together with the result that $S O C 1$ is a direct downstream target of $A B F 3$ and 4 transcription factors, these findings suggest that stress-responsive ABFs mediate ABA-dependent modulation of plant growth and development under stress conditions.

The function of ABFs in abiotic stress tolerance is conserved in plants. For example, ABA and abiotic stress upregulate the Fagopyrum tataricum FtbZIP5 and Poncirus trifoliata PtrABF bZIP transcription factors. FtbZIP5-overexpressing Arabidopsis plants exhibited improved tolerance to drought, salinity, 
and oxidative stress by modulating the antioxidant system [39]. Similar to FtbZIP5, overexpression of PtrABF enhanced abiotic stress tolerance in tobacco [40]. This indicates functional conservation of stress-responsive bZIPs in plants, suggesting that modulation of the stress-responsive bZIPs could be a good strategy for development of crops with improved stress tolerance. For example, ABA and abiotic stress induce the expression of rice (Oryza sativa) OsbZIP23 [41] and transactivation assays showed that OsbZIP23 is a transcriptional activator. Overexpression of OsbZIP23 increased sensitivity to ABA and improved the tolerance to abiotic stress, including drought and salinity.

Other stress-responsive rice bZIPs showed similar functions in abiotic stress tolerance to that of OsbZIP23. For example, OsbZIP12 and OsbZIP71 conferred drought tolerance by increasing sensitivity to ABA, and OsbZIP46 and OsbZIP72 improved drought tolerance in rice and Arabidopsis [36,42-46]. $\mathrm{ZmbZIP4}$ is a stress-responsive maize (Zea mays) bZIP transcription factor with high sequence similarity to OsbZIP23 [47]. Similar to OsbZIP23, overexpression of ZmbZIP4 increased ABA levels and enhanced abiotic stress tolerance by activating the transcription of stress-responsive genes. Interestingly, ZmbZIP4 also affects expression of genes involved in root development in maize, such as ZmLRP1, ZmSCR, $Z m I A A s$, and ZmARFs, and ZmbZIP4-overexpressing transgenic plants formed longer roots with an increased number of lateral roots. These results suggest that ZmbZIP4 positively regulates plant abiotic stress responses and is involved in root development in maize [47].

\section{JA Signaling and MYC Transcription Factors}

\subsection{JA Metabolism}

JA regulates plant responses to environmental stresses and modulates development under stress conditions [48,49]. JA, a cyclopentane fatty acid, and was initially isolated as a methyl ester from Jasminum grandiflorum. JA is biosynthesized from linolenic acid via the octadecanoid pathway involving a variety of enzymatic components, such as lipoxygenase (LOX), allene oxide synthase (AOS), allene oxide cyclase (AOC), and 12-oxo-PDA reductase (OPR) [50,51]. The free acid form of JA, which is produced through the octadecanoid pathway, is further metabolized into the JA-isoleucine conjugate (JA-Ile) or methyl jasmonate (MeJA) through the activity of jasmonate-amido synthetase 1 (JAR1) and jasmonate methyl transferase (JMT), respectively [52,53]. JA-Ile is an active form of JA that interacts with JA receptors to promote the JA-dependent stress response [54]. In response to abiotic stress, the expression of JA biosynthesis genes is dynamically upregulated, leading to increases in endogenous JA levels. For example, cold temperature stress rapidly activated the JA response by inducing expression of JA biosynthesis genes such as LOX, AOS, and AOC in Arabidopsis and rice $[55,56]$. Furthermore, exogenous JA treatments improved freezing tolerance, and the JA-deficient mutants lox2 and aos exhibited reduced tolerance to freezing compared to wild-type plants [55]. In addition, transgenic Arabidopsis plants overexpressing wheat (Triticum aestivum) AOC1 (TaAOC1) showed enhanced tolerance to salt stress by activating JA biosynthesis $[57,58]$. These studies support the view that JA is a key hormone mediating plant responses and tolerance to abiotic stress, indicating that JA metabolism is a key step controlling the JA response in plants. Similar to ABA, JA transport remains largely unknown. A radioisotopic labeling experiment suggested that JA is transported both through phloem and xylem [59]. However, a recent study using a micrografting experiment suggested shoot-to-root JA transport mainly though phloem, and this finding is partially supported by phloem-specific accumulation of JA biosynthetic enzymes such as LOX and AOS [60,61].

\subsection{JA Signaling and MYC Transcription Factors}

Early studies on JA revealed that the expression of genes involved in plant defenses is rapidly and dynamically regulated by exogenous JA treatment, indicating the existence of a JA-specific signaling pathway and the integral role of JA in modulating stress-related transcription networks $[62,63]$. In Arabidopsis, identification of JA signaling components, including the JA receptor CORONATINE INSENSITIVE 1 (COI1) and the JA signaling repressors JASMONATE ZIM-DOMAIN proteins 
(JAZs), have extended our understanding of the JA signaling pathway and establishment of JA-dependent transcription. In response to abiotic stress, JA, especially JA-Ile, activates JA signaling through interaction with COI1. This interaction induces $26 \mathrm{~S}$ proteasome-mediated proteolysis of JAZs. In the absence of JA, the activity of the MYC2 transcription factor, which governs the expression of JA-dependent stress-responsive genes, is suppressed through its interaction with JAZ proteins. The degradation of JAZs liberates MYC2, which then activates the expression JA-responsive genes [64-67] (Figure 2). This indicates a pivotal role of MYC2 in the JA response, and the finding that expression of $M Y C 2$ is regulated by diverse abiotic stresses, including drought and salinity, suggests that MYC2 is involved in the plant response and tolerance to abiotic stress [68-70]. MYC2 was identified in a mutant screen for insensitivity to exogenous JA, and further characterization revealed that MYC2 is a key component of the JA signaling pathway [71]. MYC2 contains a conserved bHLH domain required for the formation of homo- or hetero-dimers with other JA-responsive MYCs such as MYC3 and MYC4 [72]. The basic region of the MYC2 protein is responsible for its interaction with DNA (G-box; 5'-CACGTG-3') [73]. Expression of MYC2 is involved in the plant response and tolerance to abiotic stress such as oxidative stress. Ascorbate is a major reactive oxygen species (ROS) scavenger in plants [74]. Exogenous JA treatment increases ascorbate levels by inducing ascorbate biosynthesis genes such as DEHYDROASCORBATE REDUCTASE and ASCORBATE PEROXIDASE, and knock-out mutant plants that lack MYC activity display reduced expression of genes involved in oxidative stress tolerance $[69,75]$. This suggests that MYC2 positively regulates oxidative stress tolerance, and the result that $M Y C 2$-overexpressing transgenic plants show improved tolerance to oxidative stress further supports this.

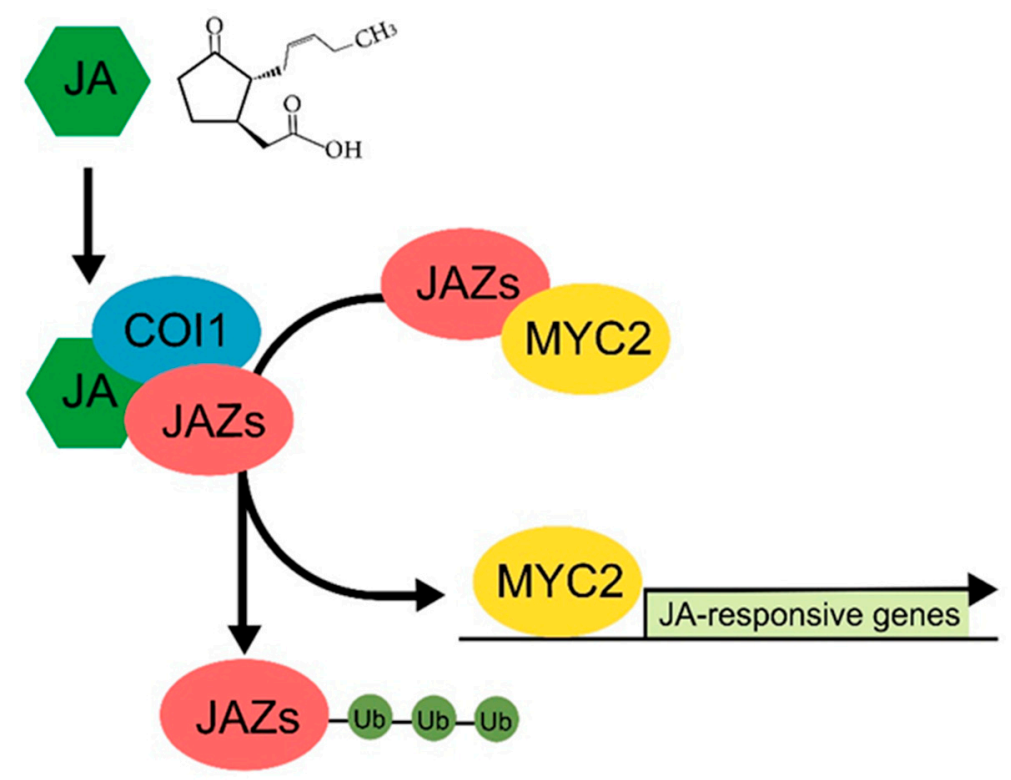

Figure 2. A schematic of JA signaling pathway. MYC2 is a key transcription factor responsible for expression of JA-responsive genes. In the absence of JA, the transcription activity of MYC2 is suppressed by direct interaction with JAZs. In JA condition, JA interacts with the JA receptor COI1 and provokes ubiquitin ( $\mathrm{Ub}$ )-mediated proteolysis of JAZs, leading to activation of MYC2 and expression of JA-responsive genes.

MYC transcription factors, which are characterized by the basic helix-loop-helix (bHLH) domain, belong to a subfamily of bHLH transcription factors [76,77]. The family of bHLH transcription factors is widespread in eukaryotes, and has expanded in plants [78,79]. Based on the sequence similarity of the bHLH domain, it has been suggested that Arabidopsis contains approximately $160 \mathrm{bHLH}$ transcription factors, and many bHLH transcription factors, including AtbHLH17, AtbHLH68, and AtbHLH122, are involved in plant abiotic stress responses [80-83]. The function of bHLH transcription factors in 
abiotic stress tolerance is conserved in plants, as supported by studies showing that heterologous expression of F. tataricum FtbHLH2 and 3, and Populus euphratica PebHLH35 in Arabidopsis enhanced tolerance to abiotic stresses, such as cold, drought, and oxidative stress [82,84,85].

In rice, OsbHLH148 has a similar activity to MYC2 [86]. OsbHLH148 directly interacts with JAZ proteins, suggesting that OsbHLH148 act as a JA signaling component in rice. The expression of OsbHLH148 is rapidly upregulated by JA and diverse abiotic stresses such as drought, salinity, cold, and wounding. Furthermore, transgenic rice overexpressing OsbHLH148 exhibited increased transcript levels of DEHYDRATION-RESPONSIVE ELEMENT-BINDING PROTEINS (OsDREBs), which are involved in the drought-stress response, and displayed enhanced tolerance to drought [86]. This suggests that stress-responsive bHLH transcription factors, including MYC2 and OsbHLH148, play an essential role in plant response and tolerance to abiotic stress. Indeed, studies using stress-responsive bHLH transcription factors, such as INDUCER OF CBF EXPRESSION 1 (ICE1) and ICE2, support this $[55,87]$.

In addition, stress-responsive bHLH transcription factors, including MYC2 and OsbHLH148, are involved in ABA-mediated stress tolerance [86,88]. Expression of MYC2 and OsbHLH148 is strongly upregulated by ABA and ABA-related stresses. In addition, MYC2 promotes the expression of $\mathrm{ABA}$ and the dehydration-responsive gene $r d 22$ by directly interacting with its promoter, and $m y c 2$ mutant plants show reduced sensitivity to ABA [88]. These results suggest that JA interacts with ABA to modulate stress response and tolerance, and stress-responsive bHLH transcription factors are involved in the JA-ABA crosstalk. This idea is supported by increasing evidence showing that ABA is involved in modulation of stress tolerance by stress-responsive bHLH transcription factors [89-91]. In addition, the results showing that activation of JA biosynthesis by jasmonic acid methyltransferase (JMT) promotes ABA production, and that the ABA receptor PYL6/RCAR9 interacts with MYC2 also support this $[92,93]$.

\section{Other Transcription Factors Involved in Plant Tolerance to Abiotic Stress}

\subsection{NAC Transcription Factors}

NAC (NO APICAL MERISTEM (NAM), ARABIDOPSIS TRANSCRIPTION ACTIVATOR FACTOR 1/2 (ATAF1/2), and CUP-SHAPED COTYLEDON 2 (CUC2)) transcription factors are plant-specific transcription factors [94,95]. Plants contain more than 100 NAC transcription factors, indicating that the NACs constitute one of the largest families of transcriptional regulators in plants. This suggests that NAC-dependent transcription networks are involved in many biological processes in plants [96,97]. NAC transcription factors contain a conserved NAC domain in the N-terminal region and a regulatory domain in the $\mathrm{C}$-terminal region, which are responsible for DNA binding and transcriptional regulation, respectively [98,99]. The expression of many NACs is regulated by abiotic stress. For example, Jiang and Deyholos (2006) reported that the expression of 33 NAC genes was significantly upregulated by salt stress in Arabidopsis [100], and Fang et al. (2008) and Le et al. (2011) reported that the expression of approximately 40 NACs was upregulated in response to abiotic stresses, such as drought and salinity, in rice and soybean $[101,102]$. These studies suggested that stress-responsive NACs are involved in plant abiotic stress responses. Indeed, many studies of stress-responsive NACs including ANAC019, ANAC055, ANAC072, OsNAC6, OsNAC5, OsNAC9, and OsNAC10, have demonstrated this [103-107].

EARLY RESPONSIVE TO DEHYDRATION STRESS 1 (ERD1), encoding a chloroplast ATP-dependent protease, is involved in the response to abiotic stresses [108]. ERD1 expression is tightly regulated by abiotic stress, and the stress-responsive expression pattern of ERD1 largely depends on a CATGTG motif in its promoter. ANAC019, ANAC055, and ANAC072, which interact with the motif, are responsible for the expression of ERD1 [103], and further characterization of ANAC019, ANAC055, and ANAC072 revealed that their expression is induced by diverse abiotic stresses, such as drought and salinity, and by ABA, and overexpression of these NACs significantly increases drought tolerance. In contrast to the overexpressing plants, mutant plants that lack the 
activity of ANAC019, ANAC055, and ANAC072 displayed reduced tolerance to salt stress compared to wild-type control plants [109]. These findings suggest that stress-responsive NACs play a crucial role in plant tolerance to abiotic stress, and the results of other stress-responsive NACs, such as RD26 and ANAC042, support this [7,110].

The function of stress-responsive NACs is conserved in plants. Heterologous overexpression of Arabidopsis ANAC042/AtJUB1 improved abiotic stress tolerance in tomato (Solanum lycopersicum) and Arabidopsis $[110,111]$. In addition, transgenic Arabidopsis plants expressing stress-responsive wheat TaNAC29 exhibited enhanced tolerance to high salinity by reducing the accumulation of hydrogen peroxide [112]. This suggests that stress-responsive NACs would be good targets for improvement of abiotic stress tolerance in crops. For example, OsNAC6 is a rice NAC transcription factor, and its expression is upregulated by a variety of abiotic stresses [104]. OsNAC6-overexpressing transgenic rice showed enhanced tolerance to drought, whereas OsNAC6 knock-out mutants displayed reduced tolerance compared to wild-type control plants. This indicated that OsNAC6 positively regulates abiotic stress tolerance [112]. In addition, genome-wide transcription profiling revealed that OsNAC6 regulates the expression of nicotianamine biosynthesis genes such as NICOTIANAMINE SYNTHASE 2 (NAS2), and overexpression of NAS2 improved tolerance to drought. These findings suggest that OsNAC6 modulates plant tolerance to drought by regulating nicotianamine biosynthesis [113].

The essential role of stress-responsive OsNACs in stress tolerance was also shown in other studies using OsNAC5, OsNAC9, and OsNAC10. Similar to OsNAC6, expression of OsNAC5, OsNAC9, and OsNAC10 is activated by abiotic stress, and overexpression of these transcription factors significantly improved drought tolerance [105-107]. Consequently, grain yields of the OsNACs-overexpressing transgenic rice plants were higher than that of wild-type control plants under stress conditions. Unlike these NACs, OsNAC2 negatively regulates plant tolerance to drought stress [114], suggesting that stress-responsive transcription factors including NACs are involved in negative regulation of plant tolerance to abiotic stresses [115]. Previous studies also show that NACs mediate modulation of plant growth and development under stress conditions. For example, overexpression of OsNAC5, OsNAC9, and OsNAC10 promoted root growth, suggesting that these stress-responsive NACs are involved in developmental changes under stress conditions [116]. A wheat NAC transcription factor, TaRNAC1, showed a similar function to the rice NACs; overexpression of TaRNAC1 resulted in enhanced dehydration tolerance, and promoted root growth in wheat [117].

Despite the crucial role of NAC transcription factors in abiotic stress tolerance, the regulatory interactions between NACs and ABA, or NACs and JA remain largely unknown. However, increasing evidence suggests that NACs cooperate with $\mathrm{ABA}$ and JA to modulate plant responses and tolerance to abiotic stress. For example, the expression of many NACs is regulated by ABA and JA, as well as abiotic stress $[103,105-107,118]$. Furthermore, the Arabidopsis NAC transcription factor ANAC096 directly interacts with $\mathrm{ABF} 2$ and 4, which are key transcription factors of $\mathrm{ABA}$ signaling, to regulate dehydration and osmotic stress responses, and the Arabidopsis NAC transcription factor VASCULAR-RELATED NAC-DOMAIN-INTERACTING 2 (VNI2) integrates ABA signals into leaf senescence [119,120]. In addition, ANAC019 and ANAC055 regulate the JA-signaled defense response, and the rice NAC transcription factor RIM1 functions as a regulator of JA signaling [121,122]. These findings suggest that NACs are fundamentally involved in ABA- and JA-mediated modulation of abiotic stress responses in plants.

\subsection{AP2/ERF Transcription Factors}

The APETALA 2/ETHYLENE-RESPONSIVE FACTOR (AP2/ERF) transcription factor family comprises a large group of plant-specific transcription factors (122 AP2/ERFs in Arabidopsis and 139 in rice) that includes four major subfamilies, AP2, RELATED TO ABSCISIC ACID INSENSITIVE 3/VIVIPAROUS 1 (RAV), ETHYLENE-RESPONSIVE FACTOR (ERF), and DEHYDRATION-RESPONSIVE ELEMENT-BINDING PROTEIN (DREB) [123-125]. Genome-wide transcription profiling studies showed that expression of most AP2/ERFs is activated by abiotic 
stress, and this activation largely depends on the stress or ABA-responsive cis-elements of their promoter regions. For example, the Arabidopsis AP2/ERF transcription factor DREB2A plays a key role in controlling plant tolerance to abiotic stresses such as drought, and the expression of $D R E B 2 A$ is controlled by a direct interaction between stress-signaling proteins, such as ABFs and the ABA-Responsive Element (ABRE) of the DREB2A promoter [126,127]. AP2/ERF transcription factors contain an AP2 domain consisting of approximately 60 amino acids in the $\mathrm{N}$-terminal region and a regulatory domain in the C-terminal region, which are responsible for the activity of DNA binding and transcriptional regulation, respectively [125].

AP2/ERFs play an essential role in plant response and tolerance to abiotic stress by regulating the expression of stress-responsive genes. DREB1s/C-REPEAT-BINDING FACTORS (CBFs), belonging to the AP2/ERF transcription factor family, are key regulators of plant response to cold temperature stress [128]. Expression of DREB1s/CBFs is strongly upregulated by cold, and overexpression of $D R E B 1 s$ enhances plant tolerance to freezing stress in Arabidopsis. In contrast to the overexpressing plants, knock-out mutants that lack the activity of DREB1s displayed reduced tolerance to freezing temperatures, indicating a pivotal role of DREB1s in cold stress tolerance [129]. Expression of DREB1s also affects plant tolerance to drought and salt stress, and it is likely that expression of a common set of stress-responsive gene is involved in this phenomenon $[125,130,131]$. The crucial role of AP2/ERFs in plant stress tolerance was also shown in other subfamilies of the AP2/ERFs in Arabidopsis. AtERF53 is a stress-responsive AP2/ERF transcription factor and its overexpression confers enhanced tolerance to heat stress and drought in Arabidopsis [132,133]. Similar to AtERF53, transgenic plants overexpressing AtERF74 displayed enhanced tolerance to drought, whereas AtERF74 knock-out mutants exhibited reduced tolerance [133]. Furthermore, the peanut (Arachis hypogaea) AP2/ERF transcription factor AhDREB1 improved tolerance to osmotic stress in Arabidopsis [134]. These studies indicate a crucial role of AP2/ERFs in stress tolerance, and that the function of stress-responsive AP2/ERFs is conserved in plants.

Because of the essential role of AP2/ERFs in stress tolerance, many studies have aimed to identify and characterize stress-responsive AP2/ERFs in crops. For example, the rice stress-responsive AP2/ERFs OsDREB1, OsEREBP1, and OsERF71 mediate abiotic stress responses in rice. The expression of OsDREB1, OsEREBP1, and OsERF71 is regulated by abiotic stress, and their overexpression improved abiotic stress tolerance in rice by regulating the expression of stress-responsive genes [135-139]. Interestingly, the stress-responsive OsERF71 also regulates lignin biosynthesis by directly regulating the expression of lignin biosynthesis genes such as CINNAMOYL-COENZYME A REDUCTASE 1 [137]. Lignin biosynthesis affects drought stress because lignin, a key component of plant secondary cell walls, is hydrophobic and inhibits water loss from plant tissues [140]. Indeed, drought-tolerant inbred lines displayed increased levels of lignin compared to drought-sensitive lines in maize [141]. These studies suggest that OsERF71 regulates plant tolerance to drought stress by controlling lignin biosynthesis. Many stress-responsive AP2/ERFs have been identified in other crops besides rice, including soybean ERF3, maize DREB2A, and tomato SIERF5, based on their stress-responsive expression patterns and functions in abiotic stress tolerance [17,142-144]. This further suggests that AP2/ERF transcription factors are critical for meditating plant response and tolerance to abiotic stress.

It has been suggested that DREBs regulate plant response to abiotic stress in an ABA-independent manner [145]. However, increasing evidence suggests that several stress-responsive AP2/ERFs are involved in ABA-dependent stress responses $[17,132,134,137,139,146]$. Furthermore, a study by Feng et al. (2014) showed that the AP2/ERF transcription factor RAV1 directly interacts with SnRK2s, which are key kinases that determine the activity of ABFs, and regulates ABA sensitivity [147]. This finding supports the idea that some AP2/ERF transcription factors are involved in ABA-dependent stress responses. In addition, a recent study showed that OCTADECANOID-RESPONSIVE AP2/ERF TRANSCRIPTION FACTOR 47 (ORA47) regulates the biosynthesis of JA, suggesting that AP2/ERFs might be involved in modulation of JA -mediated plant responses [17]. 


\subsection{MYB Transcription Factors}

MYB transcription factors are named for the conserved MYB domain responsible for DNA binding, and constitute a large family of transcription factors [148]. The MYB domain is composed of approximately 50 amino acids and MYB transcription factors are divided into four subfamilies based on the number and the position of MYB repeats: 1R-, R2R3, R1R2R3-, and 4R-MYB [149]. R2R3-MYBs are plant-specific MYB transcription factors, and it has been suggested that plants have approximately 100 R2R3-MYBs [150,151]. Genome-wide transcription profiling showed that expression of many MYBs and genes with MYB-binding elements are regulated by abiotic stresses such as drought [152-155], suggesting that MYBs are involved in plant responses and tolerance to abiotic stress. MYBs tend to interact with other transcription factors, and direct interaction between MYBs and stress-responsive transcription factors, such as MYCs and WRKYs, support the finding that MYBs are involved in plant response and tolerance to abiotic stresses [156-158]. The role of MYBs in abiotic stress response have been further demonstrated by functional characterization studies using overexpression and knock-out systems. For example, AtMYB44 regulates drought tolerance in Arabidopsis [159]. AtMYB44 is specifically expressed in guard cells, and the expression is activated by abiotic stresses such as drought, cold, and salinity. Furthermore, overexpression of Arabidopsis AtMYB44 increases ABA sensitivity and ABA-induced stomatal closure, leading to improved tolerance to drought stress. By contrast, atmyb44 knockout plants displayed increased sensitivity to drought stress, indicating that AtMYB44 positively regulates drought tolerance by modulating ABA-dependent stomatal closure [159]. AtMYB96 is also involved in drought tolerance in Arabidopsis [160,161]. Expression of AtMYB96 is induced by drought and ABA, and overexpression of AtMYB96 enhanced drought resistance by activating cuticular wax biosynthesis, which inhibited water loss through the leaf surface. This result is supported by a study in Camelina sativa in which heterologous overexpression of AtMYB96 resulted in improved drought tolerance via cuticular wax accumulation, similar to Arabidopsis [162], suggesting that the function of AtMYB96 in cuticular wax synthesis and drought tolerance is conserved among plants.

MYBs are also involved in salt stress. Expression of AtMYB20 is upregulated by salt stress, and transgenic plants overexpressing AtMYB20 showed improved tolerance to salt stress [163]. By contrast, suppression of $A t M Y B 20$ resulted in hypersensitivity to salt stress, indicating that AtMYB20 positively regulates plant tolerance to salt stress. Similar to Arabidopsis, many stress-responsive MYBs have been identified in crops, including rice and soybean, based on their expression patterns and functions in abiotic stress tolerance. For example, OsMYB4, OsMYB6, OsMYB48-1, and OsMYB91 were identified in rice, and GmMYB76, GmMYB92, and GmMYB177 in soybean [164-168]. The interaction between MYBs and ABA is largely unknown, but several studies showing that the expression of many stress-responsive $M Y B s$ is also regulated by ABA and JA suggest that MYBs are involved in modulation of ABA- and JA-dependent stress responses. This is partially supported by studies showing that $A t M Y B 20$ suppresses the expression of $P P 2 C$, which encode negative regulators of ABA signaling, and AtMYB21 and 24 directly interact with the JA signaling repressors JAZs [169].

\subsection{WRKY Transcription Factors}

WRKY transcription factors contain a highly conserved WRKYGQK motif in their N-terminal region and a novel zinc-finger-like motif at their C-terminal region [170]. WRKY transcription factors constitute a large family in plants. For example, the Arabidopsis, rice, and soybean genomes are predicted to have approximately 74, 103, and 197 WRKYs, respectively [170-172]. Stress-responsive expression patterns of WRKYs have suggested their involvement in plant response to abiotic stress. For example, a microarray analysis showed that the expression of $18 W R K Y_{S}$ (among $35 W R K Y_{S}$ tested) is induced by salt stress [100]. The involvement of WRKYs in plant stress responses has been demonstrated through functional characterization using knock-out or overexpression systems. In Arabidopsis, heat stress affects the expression of AtWRKY25, 26, and 33 [173]. In normal growth conditions, germination and growth of wrky 25 wrky 26 and wrky 25 wrky33 double mutants and the wrky 25 wrky 26 wrky33 triple mutant were similar to those of wild-type control plants. However, these mutants were 
hypersensitive to heat stress, and their survival rate was significantly decreased. By contrast, transgenic plants overexpressing WRKY25, WRKY26, and WRKY33 displayed enhanced tolerance to heat stress, providing evidence that WRKY25, WRKY26, and WRKY33 positively regulate plant tolerance to heat stress. Similarly, heat stress-responsive WRKY39 also positively regulates heat stress tolerance [174]. In addition, increasing evidence suggests that WRKYs are involved in modulating development under stress conditions, similar to NACs and AP2/ERFs. For example, stress-responsive WRKY46 modulates the development of lateral roots under abiotic stress conditions, and WRKY22 mediates dark-induced senescence $[175,176]$. Despite the crucial role of WRKYs, the interaction between WRKYs and ABA in abiotic stress response remains largely unknown; however, findings that the expression of WRKYs, such as AtWRKY18, AtWRKY40, AtWRKY60, AtWRKY63, and GhWRKY17, affects the ABA response suggest that WRKYs are involved in ABA-mediated abiotic stress signaling [177-179].

Several WRKYs have been identified in crops and functionally characterized through gain-of-function studies. Overexpression of the stress-induced rice OsWRKY11 and OsWRKY45 enhanced drought tolerance, and heterologous overexpression of wheat TaWRKY1 and TaWRKY33 also improved drought tolerance in Arabidopsis [180-182]. These studies suggest that the function of stress-responsive WRKYs is conserved in plants, and also propose that stress-responsive WRKYs may be promising target genes for improving abiotic stress tolerance in crops. The transcription factors described in this review were summarized in Table 1.

Table 1. Transcription factors that mediate plants tolerance to abiotic stress.

\begin{tabular}{ccccc}
\hline Family & Gene & Species & Abiotic tolerance & Reference \\
\hline ABF3 & Arabidopsis thaliana & Drought & {$[36]$} \\
ABF4 & Arabidopsis thaliana & Drought & {$[36]$} \\
FtbZIP5 & Fagopyrum tataricum & Drought, salinity, oxidative & {$[39]$} \\
PtrABF & Poncirus trifoliate & Drought & {$[40]$} \\
bZIP & OsbZIP23 & Oryza sativa & Drought, salinity & {$[41]$} \\
& OsbZIP12 & Oryza sativa & Drought & {$[42]$} \\
& OsbZIP71 & Oryza sativa & Drought, salinity & {$[45]$} \\
OsbZIP46 & Oryza sativa & Drought & {$[43]$} \\
& OsbZIP72 & Oryza sativa & Drought & {$[44]$} \\
ZmbZIP4 & Zea mays & Salinity & {$[47]$} \\
\hline MYC2 & Arabidopsis thaliana & Oxidative & {$[69]$} \\
bHLH & Arabidopsis thaliana & Salinity, oxidative & {$[80]$} \\
& AtbHLH17 & Drought & {$[81]$} \\
AtbHLH68 & Arabidopsis thaliana & Salinity & {$[83]$} \\
AtbHLH122 & Arabidopsis thaliana & Freezing & {$[84]$} \\
FtbHLH2 & Fagopyrum tataricum & Drought, oxidative & {$[82]$} \\
FtbHLH3 & Fagopyrum tataricum & Drought & {$[85]$} \\
PebHLH35 & Populus euphratica & Drought & {$[86]$} \\
\hline OsbHLH148 & Oryza sativa & Drought & {$[103]$} \\
& ANAC019 & Arabidopsis thaliana & Drought & {$[103]$} \\
ANAC055 & Arabidopsis thaliana & Drought & {$[103]$} \\
ANAC072 & Arabidopsis thaliana & Heat & {$[110]$} \\
ANAC042 & Arabidopsis thaliana & Salinity & {$[113]$} \\
TaNAC29 & Triticum aestivum & Drought & {$[112]$} \\
OsNAC6 & Oryza sativa & Drought & {$[105]$} \\
OsNAC5 & Oryza sativa & Drought & {$[106]$} \\
OsNAC9 & Oryza sativa & Drought & {$[117]$} \\
\hline OsNAC10 & Oryza sativa & Drought & \\
\hline
\end{tabular}


Table 1. Cont.

\begin{tabular}{|c|c|c|c|c|}
\hline Family & Gene & Species & Abiotic tolerance & Reference \\
\hline \multirow{12}{*}{$\mathrm{AP} 2 / \mathrm{ERF}$} & $C B F 1$ & Arabidopsis thaliana & Freezing, salinity & {$[128,129]$} \\
\hline & $C B F 2$ & Arabidopsis thaliana & Freezing, salinity & {$[128,129]$} \\
\hline & $C B F 3$ & Arabidopsis thaliana & Freezing, salinity & {$[128,129]$} \\
\hline & AtERF53 & Arabidopsis thaliana & Heat & [132] \\
\hline & AtERF74 & Arabidopsis thaliana & Drought & [133] \\
\hline & AhDREB1 & Arachis hypogaea & Osmosis & [134] \\
\hline & OsDREB1 & Oryza sativa & Drought, salinity, freezing & [135] \\
\hline & OsEREBP1 & Oryza sativa & Drought, submergence & [136] \\
\hline & OsERF71 & Oryza sativa & Drought & [137-139] \\
\hline & GmERF3 & Glycine max & Salinity, drought, heat stress & [142] \\
\hline & $\mathrm{ZmDREB} 2 \mathrm{~A}$ & Zea mays & Drought, heat & [143] \\
\hline & SlERF5 & Solanum lycopersicum & Drought, salinity & [144] \\
\hline \multirow{10}{*}{ MYB } & AtMYB44 & Arabidopsis thaliana & Drought & [159] \\
\hline & AtMYB96 & Arabidopsis thaliana & Drought & [160-162] \\
\hline & AtMYB20 & Arabidopsis thaliana & Salinity & [163] \\
\hline & OsMYB4 & Oryza sativa & Freezing & [164] \\
\hline & OsMYB6 & Oryza sativa & Drought, salinity & [165] \\
\hline & OsMYB48-1 & Oryza sativa & Drought, salinity & [166] \\
\hline & OsMYB91 & Oryza sativa & Salinity & [167] \\
\hline & GmMYB76 & Glycine max & Salinity, freezing & [168] \\
\hline & GmMYB92 & Glycine max & Salinity, freezing & [168] \\
\hline & GmMYB177 & Glycine max & Salinity, freezing & [168] \\
\hline \multirow{8}{*}{ WRKY } & AtWRKY25 & Arabidopsis thaliana & Heat & [173] \\
\hline & AtWRKY26 & Arabidopsis thaliana & Heat & [173] \\
\hline & AtWRKY33 & Arabidopsis thaliana & Heat & [173] \\
\hline & AtWRKY39 & Arabidopsis thaliana & Heat & [174] \\
\hline & OsWRKY11 & Oryza sativa & Drought & [180] \\
\hline & OsWRKY45 & Oryza sativa & Drought & [181] \\
\hline & TaWRKY1 & Triticum aestivum & Drought & [182] \\
\hline & TaWRKY33 & Triticum aestivum & Drought & [182] \\
\hline
\end{tabular}

\section{Future Perspectives}

$\mathrm{ABA}$ and JA are key hormones that mediate plant response and tolerance to abiotic stress. However, increasing evidence suggests that other phytohormones, such as auxin, cytokinin, brassinosteroid, salicylic acid and ethylene, are also involved in plant response to abiotic stress [183-185]. At present, a large number of phytohormone-derived growth regulators are used commercially in agriculture to improve plant tolerance to abiotic stresses [186-193], suggesting that identification and characterization of genetic components such as transcription factors, which mediate hormonal response, provide important clues to understand the molecular mechanisms underlying plant response and tolerance to abiotic stress, and to develop crops with improved stress tolerance. In this review, we summarized the function of stress-responsive transcription factors in modulating plant response and tolerance to abiotic stress, focusing on bZIPs, bHLHs, NACs, AP2/ERFs, MYBs, and WRKYs. However, other families of transcription factors, such as HD-ZIP and Zinc Finger transcription factors, whose expressions are regulated by abiotic stress, are also involved in plant response and tolerance to abiotic stress [194-197]. Although many of the questions about the molecular mechanisms underlying transcriptional and translational interaction between multiple transcription factors remain largely unanswered, these suggest that modulation or manipulation of transcription involved in plant stress response factors would be a good strategy to enhance tolerance to abiotic stress in crops. Numerous studies have identified and characterized the roles of stress-responsive transcription factors in plant response and tolerance to abiotic stress, but most of these studies were performed in laboratory conditions. 
Functional validation under field conditions will expand potential applications of stress-responsive transcription factors for improvement of abiotic stress tolerance in crops.

Author Contributions: G.J. and Y.Y. designed the review; Y.Y., D.H.S., H.S., H.J.K. and G.J. access information; Y.Y., D.H.S., H.S., H.J.K. and G.J. wrote the article with contributions of C.M.K. All authors have read and agreed to the published version of the manuscript.

Funding: This work was carried out with the support of the Cooperative Research Program for Agriculture Science \& Technology Development (Project No. PJ01323901 and PJ01364301 to G.J.) Rural Development Administration, Republic of Korea, and the National Research Foundation of Korea Grant funded by the Korean Government (MOE) [NRF-2019R1A2C1007103 to G.J.]. This paper was written as part of Konkuk University's research support program for its faculty on sabbatical leave in 2020 (to Y.Y.)

Conflicts of Interest: The authors declare no conflict of interest.

\section{Abbreviations}

\begin{tabular}{|c|c|}
\hline $\mathrm{ABA}$ & Abscisic acid \\
\hline JA & Jasmonic acid \\
\hline bZIP & Basic leucine zipper \\
\hline $\mathrm{ABF}$ & ABA-responsive element binding factor \\
\hline bHLH & Basic helix-loop-helix \\
\hline NCED & 9-cis-epoxycartotenoid dioxygenase \\
\hline $\mathrm{AAO}$ & Abscisic aldehyde oxidase \\
\hline SDR & Short-chain dehydrogenase/reductase \\
\hline MCSU & Molybdenum cofactor sulfurase \\
\hline UGT & UDP glucosyltransferase \\
\hline CYP707A & Cytochrome P450 monooxygenase 707A \\
\hline PYR1 & Pyrabactin resistance 1 \\
\hline PYL & Pyr-like \\
\hline RCAR & Regulatory component of aba receptor \\
\hline PP2C & Protein phosphatase type $2 \mathrm{C}$ \\
\hline SnRK2 & SNF1-related protein kinases type 2 \\
\hline ABRE & ABA-responsive element \\
\hline $\mathrm{ABI}$ & ABA-insensitive1 \\
\hline SOC1 & Suppressor of overexpression of constans 1 \\
\hline LOX & lipoxygenase \\
\hline $\mathrm{AOC}$ & Allene oxide cyclase \\
\hline ERF & Ethylene-responsive factor \\
\hline OPR & 12-oxo-PDA reductase \\
\hline JA-Ile & JA-isoleucine conjugate \\
\hline MeJA & Methyl jasmonate \\
\hline JAR1 & Jasmonate-amido synthetase 1 \\
\hline JMT & Jasmonate methyl transferase \\
\hline COI1 & Coronatine insensitive 1 \\
\hline JAZ & Jasmonate zim-domain \\
\hline ROS & Reactive oxygen species \\
\hline DREB & Dehydration-responsive element-binding protein \\
\hline ICE & Inducer of $C B F$ expression \\
\hline NAM & No apical meristem \\
\hline ATAF1/2 & Arabidopsis transcription activator factor $1 / 2$ \\
\hline CUC2 & Cup-shaped cotyledon 2 \\
\hline ERD1 & Early responsive to dehydration stress 1 \\
\hline NAS2 & Nicotianamine synthase 2 \\
\hline
\end{tabular}


VNI2 Vascular-related NAC-domain-interacting 2

AP2/ERF Apetala 2/ethylene-responsive factor

RAV Related to abscisic acid insensitive3/viviparous 1

CBF C-repeat-binding factor

ORA47 Octadecanoid-responsive AP2/ERF transcription factor 47

AOS Allene oxide synthase

\section{References}

1. Pardo, J.M. Biotechnology of water and salinity stress tolerance. Curr. Opin. Biotechnol. 2010, 21, 185-196. [CrossRef] [PubMed]

2. Joshi, R.; Wani, S.H.; Singh, B.; Bohra, A.; Dar, Z.A.; Lone, A.A.; Pareek, A.; Singla-Pareek, S.L. Transcription factors and plants response to drought stress: Current understanding and future directions. Front. Plant Sci. 2016, 7, 1029. [CrossRef] [PubMed]

3. Kimotho, R.N.; Baillo, E.H.; Zhang, Z. Transcription factors involved in abiotic stress responses in Maize (Zea mays L.) and their roles in enhanced productivity in the post genomics era. PeerJ 2019, 7, e7211. [CrossRef] [PubMed]

4. Forcat, S.; Bennett, M.H.; Mansfield, J.W.; Grant, M.R. A rapid and robust method for simultaneously measuring changes in the phytohormones ABA, JA and SA in plants following biotic and abiotic stress. Plant Methods 2008, 4, 16. [CrossRef] [PubMed]

5. Verma, V.; Ravindran, P.; Kumar, P.P. Plant hormone-mediated regulation of stress responses. BMC Plant Biol. 2016, 16, 86. [CrossRef] [PubMed]

6. Abe, H.; Urao, T.; Ito, T.; Seki, M.; Shinozaki, K.; Yamaguchi-Shinozaki, K. Arabidopsis AtMYC2 (bHLH) and AtMYB2 (MYB) function as transcriptional activators in abscisic acid signaling. Plant Cell 2003, 15, 63-78. [CrossRef] [PubMed]

7. Fujita, M.; Fujita, Y.; Maruyama, K.; Seki, M.; Hiratsu, K.; Ohme-Takagi, M.; Tran, L.S.P.; Yamaguchi-Shinozaki, K.; Shinozaki, K. A dehydration-induced NAC protein, RD26, is involved in a novel ABA-dependent stress-signaling pathway. Plant J. 2004, 39, 863-876. [CrossRef]

8. Joo, J.; Lee, Y.H.; Song, S.I. OsbZIP42 is a positive regulator of ABA signaling and confers drought tolerance to rice. Planta 2019, 249, 1521-1533. [CrossRef]

9. Zhu, J.-K. Abiotic stress signaling and responses in plants. Cell 2016, 167, 313-324. [CrossRef]

10. Zhao, Y.; Chan, Z.; Gao, J.; Xing, L.; Cao, M.; Yu, C.; Hu, Y.; You, J.; Shi, H.; Zhu, Y. ABA receptor PYL9 promotes drought resistance and leaf senescence. Proc. Natl. Acad. Sci. USA 2016, 113, 1949-1954. [CrossRef]

11. Cutler, A.J.; Krochko, J.E. Formation and breakdown of ABA. Trends Plant Sci. 1999, 4, 472-478. [CrossRef]

12. Schwartz, S.H.; Leon-Kloosterziel, K.M.; Koornneef, M.; Zeevaart, J.A. Biochemical characterization of the aba2 and aba3 mutants in Arabidopsis thaliana. Plant Physiol. 1997, 114, 161-166. [CrossRef] [PubMed]

13. Seki, M.; Narusaka, M.; Ishida, J.; Nanjo, T.; Fujita, M.; Oono, Y.; Kamiya, A.; Nakajima, M.; Enju, A.; Sakurai, T. Monitoring the expression profiles of 7000 Arabidopsis genes under drought, cold and high-salinity stresses using a full-length cDNA microarray. Plant J. 2002, 31, 279-292. [CrossRef] [PubMed]

14. Zong, W.; Tang, N.; Yang, J.; Peng, L.; Ma, S.; Xu, Y.; Li, G.; Xiong, L. Feedback regulation of ABA signaling and biosynthesis by a bZIP transcription factor targets drought-resistance-related genes. Plant Physiol. 2016, 171, 2810-2825. [CrossRef]

15. Van Moerkercke, A.; Duncan, O.; Zander, M.; Šimura, J.; Broda, M.; Bossche, R.V.; Lewsey, M.G.; Lama, S.; Singh, K.B.; Ljung, K. A MYC2/MYC3/MYC4-dependent transcription factor network regulates water spray-responsive gene expression and jasmonate levels. Proc. Natl. Acad. Sci. USA 2019, 116, 23345-23356. [CrossRef]

16. Jensen, M.K.; Lindemose, S.; De Masi, F.; Reimer, J.J.; Nielsen, M.; Perera, V.; Workman, C.T.; Turck, F.; Grant, M.R.; Mundy, J. ATAF1 transcription factor directly regulates abscisic acid biosynthetic gene NCED3 in Arabidopsis thaliana. FEBS Open Bio 2013, 3, 321-327. [CrossRef] [PubMed]

17. Chen, H.Y.; Hsieh, E.J.; Cheng, M.C.; Chen, C.Y.; Hwang, S.Y.; Lin, T.P. ORA47 (octadecanoid-responsive AP2/ERF-domain transcription factor 47) regulates jasmonic acid and abscisic acid biosynthesis and signaling through binding to a novel cis-element. New Phytol. 2016, 211, 599-613. [CrossRef] 
18. Wang, T.; Tohge, T.; Ivakov, A.; Mueller-Roeber, B.; Fernie, A.R.; Mutwil, M.; Schippers, J.H.; Persson, S. Salt-related MYB1 coordinates abscisic acid biosynthesis and signaling during salt stress in Arabidopsis. Plant Physiol. 2015, 169, 1027-1041. [CrossRef]

19. Wang, Z.-Y.; Xiong, L.; Li, W.; Zhu, J.-K.; Zhu, J. The plant cuticle is required for osmotic stress regulation of abscisic acid biosynthesis and osmotic stress tolerance in Arabidopsis. Plant Cell 2011, 23, 1971-1984. [CrossRef]

20. Kushiro, T.; Okamoto, M.; Nakabayashi, K.; Yamagishi, K.; Kitamura, S.; Asami, T.; Hirai, N.; Koshiba, T.; Kamiya, Y.; Nambara, E. The Arabidopsis cytochrome P450 CYP707A encodes ABA 8'-hydroxylases: Key enzymes in ABA catabolism. EMBO J. 2004, 23, 1647-1656. [CrossRef]

21. Umezawa, T.; Okamoto, M.; Kushiro, T.; Nambara, E.; Oono, Y.; Seki, M.; Kobayashi, M.; Koshiba, T.; Kamiya, Y.; Shinozaki, K. CYP707A3, a major ABA 8'-hydroxylase involved in dehydration and rehydration response in Arabidopsis thaliana. Plant J. 2006, 46, 171-182. [CrossRef] [PubMed]

22. Zheng, Y.; Huang, Y.; Xian, W.; Wang, J.; Liao, H. Identification and expression analysis of the Glycine max CYP707A gene family in response to drought and salt stresses. Ann. Bot. 2012, 110, 743-756. [CrossRef] [PubMed]

23. Iuchi, S.; Kobayashi, M.; Taji, T.; Naramoto, M.; Seki, M.; Kato, T.; Tabata, S.; Kakubari, Y.; Yamaguchi-Shinozaki, K.; Shinozaki, K. Regulation of drought tolerance by gene manipulation of 9-cis-epoxycarotenoid dioxygenase, a key enzyme in abscisic acid biosynthesis in Arabidopsis. Plant J. 2001, 27, 325-333. [CrossRef] [PubMed]

24. Kuromori, T.; Seo, M.; Shinozaki, K. ABA transport and plant water stress responses. Trends Plant Sci. 2018, 23, 513-522. [CrossRef] [PubMed]

25. Jia, W.; Davies, W.J. Modification of leaf apoplastic $\mathrm{pH}$ in relation to stomatal sensitivity to root-sourced abscisic acid signals. Plant Physiol. 2007, 143, 68-77. [CrossRef] [PubMed]

26. Fujita, Y.; Yoshida, T.; Yamaguchi-Shinozaki, K. Pivotal role of the AREB/ABF-SnRK2 pathway in ABRE-mediated transcription in response to osmotic stress in plants. Physiol. Plant. 2013, 147, $15-27$. [CrossRef]

27. Yoshida, T.; Fujita, Y.; Sayama, H.; Kidokoro, S.; Maruyama, K.; Mizoi, J.; Shinozaki, K.; Yamaguchi-Shinozaki, K. AREB1, AREB2, and ABF3 are master transcription factors that cooperatively regulate ABRE-dependent ABA signaling involved in drought stress tolerance and require ABA for full activation. Plant J. 2010, 61, 672-685. [CrossRef]

28. Choi, H.-I.; Hong, J.-H.; Ha, J.-O.; Kang, J.-Y.; Kim, S.Y. ABFs, a family of ABA-responsive element binding factors. J. Biol. Chem. 2000, 275, 1723-1730. [CrossRef]

29. Jakoby, M.; Weisshaar, B.; Dröge-Laser, W.; Vicente-Carbajosa, J.; Tiedemann, J.; Kroj, T.; Parcy, F. bZIP transcription factors in Arabidopsis. Trends Plant Sci. 2002, 7, 106-111. [CrossRef]

30. Umezawa, T.; Sugiyama, N.; Mizoguchi, M.; Hayashi, S.; Myouga, F.; Yamaguchi-Shinozaki, K.; Ishihama, Y.; Hirayama, T.; Shinozaki, K. Type 2C protein phosphatases directly regulate abscisic acid-activated protein kinases in Arabidopsis. Proc. Natl. Acad. Sci. USA 2009, 106, 17588-17593. [CrossRef]

31. Furihata, T.; Maruyama, K.; Fujita, Y.; Umezawa, T.; Yoshida, R.; Shinozaki, K.; Yamaguchi-Shinozaki, K. Abscisic acid-dependent multisite phosphorylation regulates the activity of a transcription activator AREB1. Proc. Natl. Acad. Sci. USA 2006, 103, 1988-1993. [CrossRef] [PubMed]

32. Nakashima, K.; Yamaguchi-Shinozaki, K.; Shinozaki, K. The transcriptional regulatory network in the drought response and its crosstalk in abiotic stress responses including drought, cold, and heat. Front. Plant Sci. 2014, 5, 170. [CrossRef] [PubMed]

33. Wang, Z.; Yan, L.; Wan, L.; Huai, D.; Kang, Y.; Shi, L.; Jiang, H.; Lei, Y.; Liao, B. Genome-wide systematic characterization of bZIP transcription factors and their expression profiles during seed development and in response to salt stress in peanut. BMC Genom. 2019, 20, 1-14. [CrossRef] [PubMed]

34. Yang, Q.-Q.; Feng, K.; Xu, Z.-S.; Duan, A.-Q.; Liu, J.-X.; Xiong, A.-S. Genome-wide identification of bZIP transcription factors and their responses to abiotic stress in celery. Biotechnol. Biotechnol. Equip. 2019, 33, 707-718. [CrossRef]

35. Yoshida, T.; Fujita, Y.; Maruyama, K.; Mogami, J.; Todaka, D.; Shinozaki, K.; Yamaguchi-Shinozaki, K. Four Arabidopsis AREB/ABF transcription factors function predominantly in gene expression downstream of SnRK2 kinases in abscisic acid signalling in response to osmotic stress. Plant Cell Environ. 2015, 38, 35-49. 
36. Kang, J.-Y.; Choi, H.-I.; Im, M.-Y.; Kim, S.Y. Arabidopsis basic leucine zipper proteins that mediate stress-responsive abscisic acid signaling. Plant Cell 2002, 14, 343-357. [CrossRef]

37. Schroeder, J.I.; Kwak, J.M.; Allen, G.J. Guard cell abscisic acid signalling and engineering drought hardiness in plants. Nature 2001, 410, 327-330. [CrossRef]

38. Hwang, K.; Susila, H.; Nasim, Z.; Jung, J.-Y.; Ahn, J.H. Arabidopsis ABF3 and ABF4 transcription factors act with the NF-YC complex to regulate SOC1 expression and mediate drought-accelerated flowering. Mol. Plant 2019, 12, 489-505. [CrossRef]

39. Li, Q.; Zhao, H.; Wang, X.; Kang, J.; Lv, B.; Dong, Q.; Li, C.; Chen, H.; Wu, Q. Tartary Buckwheat Transcription Factor FtbZIP5, Regulated by FtSnRK2.6, Can Improve Salt/Drought Resistance in Transgenic Arabidopsis. Int. J. Mol. Sci. 2020, 21, 1123. [CrossRef]

40. Huang, X.-S.; Liu, J.-H.; Chen, X.-J. Overexpression of PtrABF gene, a bZIP transcription factor isolated from Poncirus trifoliata, enhances dehydration and drought tolerance in tobacco via scavenging ROS and modulating expression of stress-responsive genes. BMC Plant Biol. 2010, 10, 230. [CrossRef]

41. Xiang, Y.; Tang, N.; Du, H.; Ye, H.; Xiong, L. Characterization of OsbZIP23 as a key player of the basic leucine zipper transcription factor family for conferring abscisic acid sensitivity and salinity and drought tolerance in rice. Plant Physiol. 2008, 148, 1938-1952. [CrossRef] [PubMed]

42. Joo, J.; Lee, Y.H.; Song, S.I. Overexpression of the rice basic leucine zipper transcription factor OsbZIP12 confers drought tolerance to rice and makes seedlings hypersensitive to ABA. Plant Biotechnol. Rep. 2014, 8, 431-441. [CrossRef]

43. Tang, N.; Zhang, H.; Li, X.; Xiao, J.; Xiong, L. Constitutive activation of transcription factor OsbZIP46 improves drought tolerance in rice. Plant Physiol. 2012, 158, 1755-1768. [CrossRef] [PubMed]

44. Lu, G.; Gao, C.; Zheng, X.; Han, B. Identification of OsbZIP72 as a positive regulator of ABA response and drought tolerance in rice. Planta 2009, 229, 605-615. [CrossRef] [PubMed]

45. Liu, C.; Mao, B.; Ou, S.; Wang, W.; Liu, L.; Wu, Y.; Chu, C.; Wang, X. OsbZIP71, a bZIP transcription factor, confers salinity and drought tolerance in rice. Plant Mol. Biol. 2014, 84, 19-36. [CrossRef]

46. González-Morales, S.I.; Chávez-Montes, R.A.; Hayano-Kanashiro, C.; Alejo-Jacuinde, G.; Rico-Cambron, T.Y.; de Folter, S.; Herrera-Estrella, L. Regulatory network analysis reveals novel regulators of seed desiccation tolerance in Arabidopsis thaliana. Proc. Natl. Acad. Sci. USA 2016, 113, E5232-E5241. [CrossRef]

47. Ma, H.; Liu, C.; Li, Z.; Ran, Q.; Xie, G.; Wang, B.; Fang, S.; Chu, J.; Zhang, J. ZmbZIP4 contributes to stress resistance in maize by regulating ABA synthesis and root development. Plant Physiol. 2018, 178, 753-770. [CrossRef]

48. Wasternack, C.; Hause, B. Jasmonates: Biosynthesis, perception, signal transduction and action in plant stress response, growth and development. An update to the 2007 review in Annals of Botany. Ann. Bot. 2013, 111, 1021-1058. [CrossRef]

49. Jang, G.; Yoon, Y.; Choi, Y.D. Crosstalk with Jasmonic Acid Integrates Multiple Responses in Plant Development. Int. J. Mol. Sci. 2020, 21, 305. [CrossRef]

50. Turner, J.G.; Ellis, C.; Devoto, A. The jasmonate signal pathway. Plant Cell 2002, 14, S153-S164. [CrossRef]

51. Schaller, A.; Stintzi, A. Enzymes in jasmonate biosynthesis-structure, function, regulation. Phytochemistry 2009, 70, 1532-1538. [CrossRef] [PubMed]

52. Staswick, P.E.; Tiryaki, I. The oxylipin signal jasmonic acid is activated by an enzyme that conjugates it to isoleucine in Arabidopsis. Plant Cell 2004, 16, 2117-2127. [CrossRef] [PubMed]

53. Seo, H.S.; Song, J.T.; Cheong, J.-J.; Lee, Y.-H.; Lee, Y.-W.; Hwang, I.; Lee, J.S.; Do Choi, Y. Jasmonic acid carboxyl methyltransferase: A key enzyme for jasmonate-regulated plant responses. Proc. Natl. Acad. Sci. USA 2001, 98, 4788-4793. [CrossRef] [PubMed]

54. Fonseca, S.; Chini, A.; Hamberg, M.; Adie, B.; Porzel, A.; Kramell, R.; Miersch, O.; Wasternack, C.; Solano, R. (+)-7-iso-Jasmonoyl-L-isoleucine is the endogenous bioactive jasmonate. Nat. Chem. Biol. 2009, 5, 344-350. [CrossRef]

55. Hu, Y.; Jiang, L.; Wang, F.; Yu, D. Jasmonate regulates the inducer of CBF expression-c-repeat binding factor/DRE binding factor1 cascade and freezing tolerance in Arabidopsis. Plant Cell 2013, 25, 2907-2924. [CrossRef]

56. Du, H.; Liu, H.; Xiong, L. Endogenous auxin and jasmonic acid levels are differentially modulated by abiotic stresses in rice. Front. Plant Sci. 2013, 4, 397. [CrossRef] 
57. Qiu, Z.; Guo, J.; Zhu, A.; Zhang, L.; Zhang, M. Exogenous jasmonic acid can enhance tolerance of wheat seedlings to salt stress. Ecotoxicol. Environ. Saf. 2014, 104, 202-208. [CrossRef]

58. Zhao, Y.; Dong, W.; Zhang, N.; Ai, X.; Wang, M.; Huang, Z.; Xiao, L.; Xia, G. A wheat allene oxide cyclase gene enhances salinity tolerance via jasmonate signaling. Plant Physiol. 2014, 164, 1068-1076. [CrossRef]

59. Thorpe, M.R.; Ferrieri, A.P.; Herth, M.M.; Ferrieri, R.A. 11 C-imaging: Methyl jasmonate moves in both phloem and xylem, promotes transport of jasmonate, and of photoassimilate even after proton transport is decoupled. Planta 2007, 226, 541. [CrossRef]

60. Hause, B.; Stenzel, I.; Miersch, O.; Maucher, H.; Kramell, R.; Ziegler, J.; Wasternack, C. Tissue-specific oxylipin signature of tomato flowers: Allene oxide cyclase is highly expressed in distinct flower organs and vascular bundles. Plant J. 2000, 24, 113-126. [CrossRef]

61. Schulze, A.; Zimmer, M.; Mielke, S.; Stellmach, H.; Melnyk, C.W.; Hause, B.; Gasperini, D. Wound-induced shoot-to-root relocation of JA-Ile precursors coordinates Arabidopsis growth. Mol. Plant 2019, 12, 1383-1394. [CrossRef] [PubMed]

62. Genva, M.; Akong, F.O.; Andersson, M.X.; Deleu, M.; Lins, L.; Fauconnier, M.-L. New insights into the biosynthesis of esterified oxylipins and their involvement in plant defense and developmental mechanisms. Phytochem. Rev. 2019, 18, 343-358. [CrossRef]

63. Wang, J.; Wu, D.; Wang, Y.; Xie, D. Jasmonate action in plant defense against insects. J. Exp. Bot. 2019, 70, 3391-3400. [CrossRef] [PubMed]

64. Chini, A.; Fonseca, S.; Fernandez, G.; Adie, B.; Chico, J.; Lorenzo, O.; Garcia-Casado, G.; López-Vidriero, I.; Lozano, F.; Ponce, M. The JAZ family of repressors is the missing link in jasmonate signalling. Nature 2007, 448, 666-671. [CrossRef]

65. Thines, B.; Katsir, L.; Melotto, M.; Niu, Y.; Mandaokar, A.; Liu, G.; Nomura, K.; He, S.Y.; Howe, G.A.; Browse, J. JAZ repressor proteins are targets of the $\mathrm{SCF}^{\mathrm{CO} 1}$ complex during jasmonate signalling. Nature 2007, 448, 661-665. [CrossRef] [PubMed]

66. Yan, J.; Zhang, C.; Gu, M.; Bai, Z.; Zhang, W.; Qi, T.; Cheng, Z.; Peng, W.; Luo, H.; Nan, F. The Arabidopsis CORONATINE INSENSITIVE1 protein is a jasmonate receptor. Plant Cell 2009, 21, 2220-2236. [CrossRef] [PubMed]

67. Kazan, K.; Manners, J.M. MYC2: The master in action. Mol. Plant 2013, 6, 686-703. [CrossRef]

68. Wang, J.; Song, L.; Gong, X.; Xu, J.; Li, M. Functions of Jasmonic Acid in Plant Regulation and Response to Abiotic Stress. Int. J. Mol. Sci. 2020, 21, 1446. [CrossRef]

69. Dombrecht, B.; Xue, G.P.; Sprague, S.J.; Kirkegaard, J.A.; Ross, J.J.; Reid, J.B.; Fitt, G.P.; Sewelam, N.; Schenk, P.M.; Manners, J.M. MYC2 differentially modulates diverse jasmonate-dependent functions in Arabidopsis. Plant Cell 2007, 19, 2225-2245. [CrossRef]

70. Verma, D.; Jalmi, S.K.; Bhagat, P.K.; Verma, N.; Sinha, A.K. A bHLH transcription factor, MYC2, imparts salt intolerance by regulating proline biosynthesis in Arabidopsis. FEBS J. 2019. [CrossRef]

71. Boter, M.; Ruíz-Rivero, O.; Abdeen, A.; Prat, S. Conserved MYC transcription factors play a key role in jasmonate signaling both in tomato and Arabidopsis. Genes Dev. 2004, 18, 1577-1591. [CrossRef] [PubMed]

72. Fernández-Calvo, P.; Chini, A.; Fernández-Barbero, G.; Chico, J.-M.; Gimenez-Ibanez, S.; Geerinck, J.; Eeckhout, D.; Schweizer, F.; Godoy, M.; Franco-Zorrilla, J.M. The Arabidopsis bHLH transcription factors MYC3 and MYC4 are targets of JAZ repressors and act additively with MYC2 in the activation of jasmonate responses. Plant Cell 2011, 23, 701-715. [CrossRef] [PubMed]

73. Toledo-Ortiz, G.; Huq, E.; Quail, P.H. The Arabidopsis basic/helix-loop-helix transcription factor family. Plant Cell 2003, 15, 1749-1770. [CrossRef] [PubMed]

74. Nagata, T.; Todoriki, S.; Masumizu, T.; Suda, I.; Furuta, S.; Du, Z.; Kikuchi, S. Levels of active oxygen species are controlled by ascorbic acid and anthocyanin in Arabidopsis. J. Agric. Food Chem. 2003, 51, 2992-2999. [CrossRef] [PubMed]

75. Sasaki-Sekimoto, Y.; Taki, N.; Obayashi, T.; Aono, M.; Matsumoto, F.; Sakurai, N.; Suzuki, H.; Hirai, M.Y.; Noji, M.; Saito, K. Coordinated activation of metabolic pathways for antioxidants and defence compounds by jasmonates and their roles in stress tolerance in Arabidopsis. Plant J. 2005, 44, 653-668. [CrossRef] [PubMed]

76. Sorensen, A.M.; Kröber, S.; Unte, U.S.; Huijser, P.; Dekker, K.; Saedler, H. The Arabidopsis ABORTED MICROSPORES (AMS) gene encodes a MYC class transcription factor. Plant J. 2003, 33, 413-423. [CrossRef] [PubMed]

77. Jones, S. An overview of the basic helix-loop-helix proteins. Genome Biol. 2004, 5, 226. [CrossRef] 
78. Feller, A.; Machemer, K.; Braun, E.L.; Grotewold, E. Evolutionary and comparative analysis of MYB and bHLH plant transcription factors. Plant J. 2011, 66, 94-116. [CrossRef]

79. Goossens, J.; Mertens, J.; Goossens, A. Role and functioning of bHLH transcription factors in jasmonate signalling. J. Exp. Bot. 2017, 68, 1333-1347. [CrossRef]

80. Babitha, K.; Ramu, S.; Pruthvi, V.; Mahesh, P.; Nataraja, K.N.; Udayakumar, M. Co-expression of AtbHLH17 and AtWRKY28 confers resistance to abiotic stress in Arabidopsis. Transgenic Res. 2013, 22, 327-341. [CrossRef]

81. Le Hir, R.; Castelain, M.; Chakraborti, D.; Moritz, T.; Dinant, S.; Bellini, C. AtbHLH68 transcription factor contributes to the regulation of ABA homeostasis and drought stress tolerance in Arabidopsis thaliana. Physiol. Plant. 2017, 160, 312-327. [CrossRef] [PubMed]

82. Yao, P.-F.; Li, C.-L.; Zhao, X.-R.; Li, M.-F.; Zhao, H.-X.; Guo, J.-Y.; Cai, Y.; Chen, H.; Wu, Q. Overexpression of a tartary buckwheat gene, FtbHLH3, enhances drought/oxidative stress tolerance in transgenic Arabidopsis. Front. Plant Sci. 2017, 8, 625. [CrossRef] [PubMed]

83. Krishnamurthy, P.; Vishal, B.; Khoo, K.; Rajappa, S.; Loh, C.-S.; Kumar, P.P. Expression of AoNHX1 increases salt tolerance of rice and Arabidopsis, and bHLH transcription factors regulate AtNHX1 and AtNHX6 in Arabidopsis. Plant Cell Rep. 2019, 38, 1299-1315. [CrossRef] [PubMed]

84. Yao, P.; Sun, Z.; Li, C.; Zhao, X.; Li, M.; Deng, R.; Huang, Y.; Zhao, H.; Chen, H.; Wu, Q. Overexpression of Fagopyrum tataricum FtbHLH2 enhances tolerance to cold stress in transgenic Arabidopsis. Plant Physiol. Biochem. 2018, 125, 85-94. [CrossRef] [PubMed]

85. Dong, Y.; Wang, C.; Han, X.; Tang, S.; Liu, S.; Xia, X.; Yin, W. A novel bHLH transcription factor PebHLH35 from Populus euphratica confers drought tolerance through regulating stomatal development, photosynthesis and growth in Arabidopsis. Biochem. Biophys. Res. Commun. 2014, 450, 453-458. [CrossRef] [PubMed]

86. Seo, J.S.; Joo, J.; Kim, M.J.; Kim, Y.K.; Nahm, B.H.; Song, S.I.; Cheong, J.J.; Lee, J.S.; Kim, J.K.; Choi, Y.D. OsbHLH148, a basic helix-loop-helix protein, interacts with OsJAZ proteins in a jasmonate signaling pathway leading to drought tolerance in rice. Plant J. 2011, 65, 907-921. [CrossRef]

87. Fursova, O.V.; Pogorelko, G.V.; Tarasov, V.A. Identification of ICE2, a gene involved in cold acclimation which determines freezing tolerance in Arabidopsis thaliana. Gene 2009, 429, 98-103. [CrossRef]

88. Abe, H.; Yamaguchi-Shinozaki, K.; Urao, T.; Iwasaki, T.; Hosokawa, D.; Shinozaki, K. Role of Arabidopsis MYC and MYB homologs in drought-and abscisic acid-regulated gene expression. Plant Cell 1997, 9, 1859-1868.

89. Yang, T.; Yao, S.; Hao, L.; Zhao, Y.; Lu, W.; Xiao, K. Wheat bHLH-type transcription factor gene TabHLH1 is crucial in mediating osmotic stresses tolerance through modulating largely the ABA-associated pathway. Plant Cell Rep. 2016, 35, 2309-2323. [CrossRef]

90. Zheng, K.; Wang, Y.; Wang, S. The non-DNA binding bHLH transcription factor Paclobutrazol resistances are involved in the regulation of ABA and salt responses in Arabidopsis. Plant Physiol. Biochem. 2019, 139, 239-245. [CrossRef]

91. Waseem, M.; Li, Z. Dissecting the Role of a Basic Helix-Loop-Helix Transcription Factor, SlbHLH22, Under Salt and Drought Stresses in Transgenic Solanum lycopersicum L. Front. Plant Sci. 2019, 10, 734. [CrossRef] [PubMed]

92. Kim, E.H.; Kim, Y.S.; Park, S.-H.; Koo, Y.J.; Do Choi, Y.; Chung, Y.-Y.; Lee, I.-J.; Kim, J.-K. Methyl jasmonate reduces grain yield by mediating stress signals to alter spikelet development in rice. Plant Physiol. 2009, 149, 1751-1760. [CrossRef] [PubMed]

93. Aleman, F.; Yazaki, J.; Lee, M.; Takahashi, Y.; Kim, A.Y.; Li, Z.; Kinoshita, T.; Ecker, J.R.; Schroeder, J.I. An ABA-increased interaction of the PYL6 ABA receptor with MYC2 transcription factor: A putative link of ABA and JA signaling. Sci. Rep. 2016, 6, 1-10. [CrossRef] [PubMed]

94. Nuruzzaman, M.; Sharoni, A.M.; Kikuchi, S. Roles of NAC transcription factors in the regulation of biotic and abiotic stress responses in plants. Front. Microbiol. 2013, 4, 248. [CrossRef]

95. Ooka, H.; Satoh, K.; Doi, K.; Nagata, T.; Otomo, Y.; Murakami, K.; Matsubara, K.; Osato, N.; Kawai, J.; Carninci, P. Comprehensive analysis of NAC family genes in Oryza sativa and Arabidopsis thaliana. DNA Res. 2003, 10, 239-247. [CrossRef]

96. Dong, X.; Jiang, Y.; Yang, Y.; Xiao, Z.; Bai, X.; Gao, J.; Tan, S.; Hur, Y.; Hao, S.; He, F. Identification and expression analysis of the NAC gene family in Coffea canephora. Agronomy 2019, 9, 670. [CrossRef]

97. Olsen, A.N.; Ernst, H.A.; Leggio, L.L.; Skriver, K. NAC transcription factors: Structurally distinct, functionally diverse. Trends Plant Sci. 2005, 10, 79-87. [CrossRef] 
98. Ernst, H.A.; Olsen, A.N.; Skriver, K.; Larsen, S.; Leggio, L.L. Structure of the conserved domain of ANAC, a member of the NAC family of transcription factors. EMBO Rep. 2004, 5, 297-303. [CrossRef]

99. Jensen, M.K.; Kjaersgaard, T.; Nielsen, M.M.; Galberg, P.; Petersen, K.; O'shea, C.; Skriver, K. The Arabidopsis thaliana NAC transcription factor family: Structure-function relationships and determinants of ANAC019 stress signalling. Biochem. J. 2010, 426, 183-196. [CrossRef]

100. Jiang, Y.; Deyholos, M.K. Comprehensive transcriptional profiling of NaCl-stressed Arabidopsis roots reveals novel classes of responsive genes. BMC Plant Biol. 2006, 6, 25. [CrossRef]

101. Fang, Y.; You, J.; Xie, K.; Xie, W.; Xiong, L. Systematic sequence analysis and identification of tissue-specific or stress-responsive genes of NAC transcription factor family in rice. Mol. Genet. Genom. 2008, 280, 547-563. [CrossRef] [PubMed]

102. Le, D.T.; Nishiyama, R.; Watanabe, Y.; Mochida, K.; Yamaguchi-Shinozaki, K.; Shinozaki, K.; Tran, L.-S.P. Genome-wide survey and expression analysis of the plant-specific NAC transcription factor family in soybean during development and dehydration stress. DNA Res. 2011, 18, 263-276. [CrossRef] [PubMed]

103. Tran, L.-S.P.; Nakashima, K.; Sakuma, Y.; Simpson, S.D.; Fujita, Y.; Maruyama, K.; Fujita, M.; Seki, M.; Shinozaki, K.; Yamaguchi-Shinozaki, K. Isolation and functional analysis of Arabidopsis stress-inducible NAC transcription factors that bind to a drought-responsive cis-element in the early responsive to dehydration stress 1 promoter. Plant Cell 2004, 16, 2481-2498. [CrossRef] [PubMed]

104. Ohnishi, T.; Sugahara, S.; Yamada, T.; Kikuchi, K.; Yoshiba, Y.; Hirano, H.-Y.; Tsutsumi, N. OsNAC6, a member of the NAC gene family, is induced by various stresses in rice. Genes Genet. Syst. 2005, 80, 135-139. [CrossRef] [PubMed]

105. Jeong, J.S.; Kim, Y.S.; Redillas, M.C.; Jang, G.; Jung, H.; Bang, S.W.; Choi, Y.D.; Ha, S.H.; Reuzeau, C.; Kim, J.K. OsNAC5 overexpression enlarges root diameter in rice plants leading to enhanced drought tolerance and increased grain yield in the field. Plant Biotechnol. J. 2013, 11, 101-114. [CrossRef] [PubMed]

106. Redillas, M.C.; Jeong, J.S.; Kim, Y.S.; Jung, H.; Bang, S.W.; Choi, Y.D.; Ha, S.H.; Reuzeau, C.; Kim, J.K. The overexpression of OsNAC9 alters the root architecture of rice plants enhancing drought resistance and grain yield under field conditions. Plant Biotechnol. J. 2012, 10, 792-805. [CrossRef]

107. Jeong, J.S.; Kim, Y.S.; Baek, K.H.; Jung, H.; Ha, S.-H.; Do Choi, Y.; Kim, M.; Reuzeau, C.; Kim, J.-K. Root-specific expression of OsNAC10 improves drought tolerance and grain yield in rice under field drought conditions. Plant Physiol. 2010, 153, 185-197. [CrossRef]

108. Kiyosue, T.; Yamaguchishinozaki, K.; Shinozaki, K. Characterization of cDNA for a dehydration-inducible gene that encodes a CLP A, B-like protein in Arabidopsis thaliana L. Biochem. Biophys. Res. Commun. 1993, 196, 1214-1220. [CrossRef]

109. Li, X.-Y.; Li, L.; Liu, X.; Zhang, B.; Zheng, W.-L.; Ma, W.-L. Analysis of physiological characteristics of abscisic acid sensitivity and salt resistance in Arabidopsis ANAC mutants (ANAC019, ANAC072 and ANAC055). Biotechnol. Biotechnol. Equip. 2012, 26, 2966-2970. [CrossRef]

110. Shahnejat-Bushehri, S.; Mueller-Roeber, B.; Balazadeh, S. Arabidopsis NAC transcription factor JUNGBRUNNEN1 affects thermomemory-associated genes and enhances heat stress tolerance in primed and unprimed conditions. Plant Signal. Behav. 2012, 7, 1518-1521. [CrossRef]

111. Alshareef, N.O.; Wang, J.Y.; Ali, S.; Al-Babili, S.; Tester, M.; Schmöckel, S.M. Overexpression of the NAC transcription factor JUNGBRUNNEN1 (JUB1) increases salinity tolerance in tomato. Plant Physiol. Biochem. 2019, 140, 113-121. [CrossRef] [PubMed]

112. Lee, D.K.; Chung, P.J.; Jeong, J.S.; Jang, G.; Bang, S.W.; Jung, H.; Kim, Y.S.; Ha, S.H.; Choi, Y.D.; Kim, J.K. The rice OsNAC6 transcription factor orchestrates multiple molecular mechanisms involving root structural adaptions and nicotianamine biosynthesis for drought tolerance. Plant Biotechnol. J. 2017, 15, 754-764. [CrossRef] [PubMed]

113. Xu, Z.; Wang, C.; Xue, F.; Zhang, H.; Ji, W. Wheat NAC transcription factor TaNAC29 is involved in response to salt stress. Plant Physiol. Biochem. 2015, 96, 356-363. [CrossRef] [PubMed]

114. Shen, J.; Lv, B.; Luo, L.; He, J.; Mao, C.; Xi, D.; Ming, F. The NAC-type transcription factor OsNAC2 regulates ABA-dependent genes and abiotic stress tolerance in rice. Sci. Rep. 2017, 7, 40641. [CrossRef]

115. Shao, H.; Wang, H.; Tang, X. NAC transcription factors in plant multiple abiotic stress responses: Progress and prospects. Front. Plant Sci. 2015, 6, 902. [CrossRef]

116. Seo, D.H.; Seomun, S.; Choi, Y.D.; Jang, G. Root Development and Stress Tolerance in rice: The Key to Improving Stress Tolerance without Yield Penalties. Int. J. Mol. Sci. 2020, 21, 1807. [CrossRef] 
117. Chen, D.; Chai, S.; McIntyre, C.L.; Xue, G.-P. Overexpression of a predominantly root-expressed NAC transcription factor in wheat roots enhances root length, biomass and drought tolerance. Plant Cell Rep. 2018, 37, 225-237. [CrossRef]

118. Liu, Z.; Fu, M.; Li, H.; Chen, Y.; Wang, L.; Liu, R. Systematic analysis of NAC transcription factors in Gossypium barbadense uncovers their roles in response to Verticillium wilt. PeerJ 2019, 7, e7995. [CrossRef]

119. Xu, Z.-Y.; Kim, S.Y.; Kim, D.H.; Dong, T.; Park, Y.; Jin, J.B.; Joo, S.-H.; Kim, S.-K.; Hong, J.C.; Hwang, D. The Arabidopsis NAC transcription factor ANAC096 cooperates with bZIP-type transcription factors in dehydration and osmotic stress responses. Plant Cell 2013, 25, 4708-4724. [CrossRef]

120. Yang, S.-D.; Seo, P.J.; Yoon, H.-K.; Park, C.-M. The Arabidopsis NAC transcription factor VNI2 integrates abscisic acid signals into leaf senescence via the COR/RD genes. Plant Cell 2011, 23, 2155-2168. [CrossRef]

121. Bu, Q.; Jiang, H.; Li, C.-B.; Zhai, Q.; Zhang, J.; Wu, X.; Sun, J.; Xie, Q.; Li, C. Role of the Arabidopsis thaliana NAC transcription factors ANAC019 and ANAC055 in regulating jasmonic acid-signaled defense responses. Cell Res. 2008, 18, 756-767. [CrossRef] [PubMed]

122. Yoshii, M.; Yamazaki, M.; Rakwal, R.; Kishi-Kaboshi, M.; Miyao, A.; Hirochika, H. The NAC transcription factor RIM1 of rice is a new regulator of jasmonate signaling. Plant J. 2010, 61, 804-815. [CrossRef] [PubMed]

123. Nakano, T.; Suzuki, K.; Fujimura, T.; Shinshi, H. Genome-wide analysis of the ERF gene family in Arabidopsis and rice. Plant Physiol. 2006, 140, 411-432. [CrossRef] [PubMed]

124. Mizoi, J.; Shinozaki, K.; Yamaguchi-Shinozaki, K. AP2/ERF family transcription factors in plant abiotic stress responses. Biochim. Biophys. Acta (Bba)-Gene Regul. Mech. 2012, 1819, 86-96. [CrossRef] [PubMed]

125. Yin, Y.; Xie, Z.; Nolan, T.M.; Jiang, H. AP2/ERF transcription factor regulatory networks in hormone and abiotic stress responses in Arabidopsis. Front. Plant Sci. 2019, 10, 228.

126. Sakuma, Y.; Maruyama, K.; Osakabe, Y.; Qin, F.; Seki, M.; Shinozaki, K.; Yamaguchi-Shinozaki, K. Functional analysis of an Arabidopsis transcription factor, DREB2A, involved in drought-responsive gene expression. Plant Cell 2006, 18, 1292-1309. [CrossRef]

127. Kim, J.-S.; Mizoi, J.; Yoshida, T.; Fujita, Y.; Nakajima, J.; Ohori, T.; Todaka, D.; Nakashima, K.; Hirayama, T.; Shinozaki, K. An ABRE promoter sequence is involved in osmotic stress-responsive expression of the DREB2A gene, which encodes a transcription factor regulating drought-inducible genes in Arabidopsis. Plant Cell Physiol. 2011, 52, 2136-2146. [CrossRef]

128. Park, S.; Lee, C.M.; Doherty, C.J.; Gilmour, S.J.; Kim, Y.; Thomashow, M.F. Regulation of the Arabidopsis CBF regulon by a complex low-temperature regulatory network. Plant J. 2015, 82, 193-207. [CrossRef]

129. Zhao, C.; Zhang, Z.; Xie, S.; Si, T.; Li, Y.; Zhu, J.-K. Mutational evidence for the critical role of CBF transcription factors in cold acclimation in Arabidopsis. Plant Physiol. 2016, 171, 2744-2759.

130. Kasuga, M.; Liu, Q.; Miura, S.; Yamaguchi-Shinozaki, K.; Shinozaki, K. Improving plant drought, salt, and freezing tolerance by gene transfer of a single stress-inducible transcription factor. Nat. Biotechnol. 1999, 17, 287-291. [CrossRef]

131. Zhao, C.; Zhu, J.-K. The broad roles of CBF genes: From development to abiotic stress. Plant Signal. Behav. 2016, 11, e1215794. [CrossRef] [PubMed]

132. Hsieh, E.-J.; Cheng, M.-C.; Lin, T.-P. Functional characterization of an abiotic stress-inducible transcription factor AtERF53 in Arabidopsis thaliana. Plant Mol. Biol. 2013, 82, 223-237. [CrossRef] [PubMed]

133. Yao, Y.; He, R.J.; Xie, Q.L.; Zhao, X.H.; Deng, X.M.; He, J.B.; Song, L.; He, J.; Marchant, A.; Chen, X.Y. ETHYLENE RESPONSE FACTOR 74 (ERF74) plays an essential role in controlling a respiratory burst oxidase homolog $\mathrm{D}(\mathrm{RbohD})$-dependent mechanism in response to different stresses in Arabidopsis. New Phytol. 2017, 213, 1667-1681. [CrossRef]

134. Zhang, B.; Su, L.; Hu, B.; Li, L. Expression of AhDREB1, an AP2/ERF transcription factor gene from peanut, is affected by histone acetylation and increases abscisic acid sensitivity and tolerance to osmotic stress in Arabidopsis. Int. J. Mol. Sci. 2018, 19, 1441. [CrossRef]

135. Dubouzet, J.G.; Sakuma, Y.; Ito, Y.; Kasuga, M.; Dubouzet, E.G.; Miura, S.; Seki, M.; Shinozaki, K.; Yamaguchi-Shinozaki, K. OsDREB genes in rice, Oryza sativa L., encode transcription activators that function in drought-, high-salt-and cold-responsive gene expression. Plant J. 2003, 33, 751-763. [CrossRef]

136. Jisha, V.; Dampanaboina, L.; Vadassery, J.; Mithöfer, A.; Kappara, S.; Ramanan, R. Overexpression of an AP2/ERF type transcription factor OsEREBP1 confers biotic and abiotic stress tolerance in rice. PLoS ONE 2015, 10, e0127831. [CrossRef] [PubMed] 
137. Lee, D.-K.; Jung, H.; Jang, G.; Jeong, J.S.; Kim, Y.S.; Ha, S.-H.; Do Choi, Y.; Kim, J.-K. Overexpression of the OsERF71 transcription factor alters rice root structure and drought resistance. Plant Physiol. 2016, 172, 575-588. [CrossRef] [PubMed]

138. Lee, D.-K.; Yoon, S.; Kim, Y.S.; Kim, J.-K. Rice OsERF71-mediated root modification affects shoot drought tolerance. Plant Signal. Behav. 2017, 12, e1268311. [CrossRef] [PubMed]

139. Li, J.; Guo, X.; Zhang, M.; Wang, X.; Zhao, Y.; Yin, Z.; Zhang, Z.; Wang, Y.; Xiong, H.; Zhang, H. OsERF71 confers drought tolerance via modulating ABA signaling and proline biosynthesis. Plant Sci. 2018, 270, 131-139. [CrossRef] [PubMed]

140. Barros, J.; Serk, H.; Granlund, I.; Pesquet, E. The cell biology of lignification in higher plants. Ann. Bot. 2015, 115, 1053-1074. [CrossRef] [PubMed]

141. Hu, Y.; Li, W.C.; Xu, Y.; Li, G.; Liao, Y.; Fu, F.-L. Differential expression of candidate genes for lignin biosynthesis under drought stress in maize leaves. J. Appl. Genet. 2009, 50, 213-223. [CrossRef] [PubMed]

142. Zhang, G.; Chen, M.; Li, L.; Xu, Z.; Chen, X.; Guo, J.; Ma, Y. Overexpression of the soybean GmERF3 gene, an AP2/ERF type transcription factor for increased tolerances to salt, drought, and diseases in transgenic tobacco. J. Exp. Bot. 2009, 60, 3781-3796. [CrossRef] [PubMed]

143. Qin, F.; Kakimoto, M.; Sakuma, Y.; Maruyama, K.; Osakabe, Y.; Tran, L.S.P.; Shinozaki, K.; Yamaguchi-Shinozaki, K. Regulation and functional analysis of ZmDREB2A in response to drought and heat stresses in Zea mays L. Plant J. 2007, 50, 54-69. [CrossRef] [PubMed]

144. Pan, Y.; Seymour, G.B.; Lu, C.; Hu, Z.; Chen, X.; Chen, G. An ethylene response factor (ERF5) promoting adaptation to drought and salt tolerance in tomato. Plant Cell Rep. 2012, 31, 349-360. [CrossRef] [PubMed]

145. Lata, C.; Prasad, M. Role of DREBs in regulation of abiotic stress responses in plants. J. Exp. Bot. 2011, 62, 4731-4748. [CrossRef]

146. Meng, L.-S.; Wang, Z.-B.; Yao, S.-Q.; Liu, A. The ARF2-ANT-COR15A gene cascade regulates ABA-signaling-mediated resistance of large seeds to drought in Arabidopsis. J. Cell Sci. 2015, 128, 3922-3932. [CrossRef]

147. Feng, C.Z.; Chen, Y.; Wang, C.; Kong, Y.H.; Wu, W.H.; Chen, Y.F. Arabidopsis RAV1 transcription factor, phosphorylated by SnRK2 kinases, regulates the expression of ABI3, ABI4, and ABI5 during seed germination and early seedling development. Plant J. 2014, 80, 654-668. [CrossRef]

148. Yanhui, C.; Xiaoyuan, Y.; Kun, H.; Meihua, L.; Jigang, L.; Zhaofeng, G.; Zhiqiang, L.; Yunfei, Z.; Xiaoxiao, W.; Xiaoming, Q. The MYB transcription factor superfamily of Arabidopsis: Expression analysis and phylogenetic comparison with the rice MYB family. Plant Mol. Biol. 2006, 60, 107-124. [CrossRef]

149. Dubos, C.; Stracke, R.; Grotewold, E.; Weisshaar, B.; Martin, C.; Lepiniec, L. MYB transcription factors in Arabidopsis. Trends Plant Sci. 2010, 15, 573-581. [CrossRef]

150. Jiang, C.; Gu, J.; Chopra, S.; Gu, X.; Peterson, T. Ordered origin of the typical two-and three-repeat Myb genes. Gene 2004, 326, 13-22. [CrossRef]

151. Wilkins, O.; Nahal, H.; Foong, J.; Provart, N.J.; Campbell, M.M. Expansion and diversification of the Populus R2R3-MYB family of transcription factors. Plant Physiol. 2009, 149, 981-993. [CrossRef] [PubMed]

152. Jia, J.; Fu, J.; Zheng, J.; Zhou, X.; Huai, J.; Wang, J.; Wang, M.; Zhang, Y.; Chen, X.; Zhang, J. Annotation and expression profile analysis of 2073 full-length cDNAs from stress-induced maize (Zea mays L.) seedlings. Plant J. 2006, 48, 710-727. [CrossRef] [PubMed]

153. Jia, L.; Clegg, M.T.; Jiang, T. Evolutionary dynamics of the DNA-binding domains in putative R2R3-MYB genes identified from rice subspecies indica and japonica genomes. Plant Physiol. 2004, 134, 575-585. [CrossRef] [PubMed]

154. Golldack, D.; Lüking, I.; Yang, O. Plant tolerance to drought and salinity: Stress regulating transcription factors and their functional significance in the cellular transcriptional network. Plant Cell Rep. 2011, 30, 1383-1391. [CrossRef]

155. Pereira, S.; Guimarães, F.; Carvalho, J.; Stolf-Moreira, R.; Oliveira, M.; Rolla, A.; Farias, J.; Neumaier, N.; Nepomuceno, A. Transcription factors expressed in soybean roots under drought stress. Genet. Mol. Res. 2011, 3689-3701. [CrossRef]

156. Schweizer, F.; Fernández-Calvo, P.; Zander, M.; Diez-Diaz, M.; Fonseca, S.; Glauser, G.; Lewsey, M.G.; Ecker, J.R.; Solano, R.; Reymond, P. Arabidopsis basic helix-loop-helix transcription factors MYC2, MYC3, and MYC4 regulate glucosinolate biosynthesis, insect performance, and feeding behavior. Plant Cell 2013, 25, 3117-3132. [CrossRef] 
157. Yu, Y.-T.; Wu, Z.; Lu, K.; Bi, C.; Liang, S.; Wang, X.-F.; Zhang, D.-P. Overexpression of the MYB transcription factor MYB28 or MYB99 confers hypersensitivity to abscisic acid in arabidopsis. J. Plant Biol. 2016, 59, 152-161. [CrossRef]

158. Wang, F.; Chen, H.W.; Li, Q.T.; Wei, W.; Li, W.; Zhang, W.K.; Ma, B.; Bi, Y.D.; Lai, Y.C.; Liu, X.L. GmWRKY27 interacts with GmMYB174 to reduce expression of GmNAC29 for stress tolerance in soybean plants. Plant J. 2015, 83, 224-236. [CrossRef]

159. Jung, C.; Seo, J.S.; Han, S.W.; Koo, Y.J.; Kim, C.H.; Song, S.I.; Nahm, B.H.; Do Choi, Y.; Cheong, J.-J. Overexpression of AtMYB44 enhances stomatal closure to confer abiotic stress tolerance in transgenic Arabidopsis. Plant Physiol. 2008, 146, 623-635. [CrossRef]

160. Seo, P.J.; Xiang, F.; Qiao, M.; Park, J.-Y.; Lee, Y.N.; Kim, S.-G.; Lee, Y.-H.; Park, W.J.; Park, C.-M. The MYB96 transcription factor mediates abscisic acid signaling during drought stress response in Arabidopsis. Plant Physiol. 2009, 151, 275-289. [CrossRef]

161. Seo, P.J.; Lee, S.B.; Suh, M.C.; Park, M.-J.; Go, Y.S.; Park, C.-M. The MYB96 transcription factor regulates cuticular wax biosynthesis under drought conditions in Arabidopsis. Plant Cell 2011, 23, 1138-1152. [CrossRef]

162. Lee, S.B.; Kim, H.; Kim, R.J.; Suh, M.C. Overexpression of Arabidopsis MYB96 confers drought resistance in Camelina sativa via cuticular wax accumulation. Plant Cell Rep. 2014, 33, 1535-1546. [CrossRef]

163. Cui, M.H.; Yoo, K.S.; Hyoung, S.; Nguyen, H.T.K.; Kim, Y.Y.; Kim, H.J.; Ok, S.H.; Yoo, S.D.; Shin, J.S. An Arabidopsis R2R3-MYB transcription factor, AtMYB20, negatively regulates type $2 \mathrm{C}$ serine/threonine protein phosphatases to enhance salt tolerance. FEBS Lett. 2013, 587, 1773-1778. [CrossRef]

164. Vannini, C.; Locatelli, F.; Bracale, M.; Magnani, E.; Marsoni, M.; Osnato, M.; Mattana, M.; Baldoni, E.; Coraggio, I. Overexpression of the rice Osmyb4 gene increases chilling and freezing tolerance of Arabidopsis thaliana plants. Plant J. 2004, 37, 115-127. [CrossRef]

165. Tang, Y.; Bao, X.; Zhi, Y.; Wu, Q.; Yin, X.; Zeng, L.; Li, J.; Zhang, J.; He, W.; Liu, W. Overexpression of a MYB family gene, OsMYB6, increases drought and salinity stress tolerance in transgenic rice. Front. Plant Sci. 2019, 10, 168. [CrossRef]

166. Xiong, H.; Li, J.; Liu, P.; Duan, J.; Zhao, Y.; Guo, X.; Li, Y.; Zhang, H.; Ali, J.; Li, Z. Overexpression of OsMYB48-1, a novel MYB-related transcription factor, enhances drought and salinity tolerance in rice. PLoS ONE 2014, 9, e92913. [CrossRef]

167. Zhu, N.; Cheng, S.; Liu, X.; Du, H.; Dai, M.; Zhou, D.-X.; Yang, W.; Zhao, Y. The R2R3-type MYB gene OsMYB91 has a function in coordinating plant growth and salt stress tolerance in rice. Plant Sci. 2015, 236, 146-156. [CrossRef]

168. Liao, Y.; Zou, H.-F.; Wang, H.-W.; Zhang, W.-K.; Ma, B.; Zhang, J.-S.; Chen, S.-Y. Soybean GmMYB76, GmMYB92, and GmMYB177 genes confer stress tolerance in transgenic Arabidopsis plants. Cell Res. 2008, 18, 1047-1060. [CrossRef]

169. Song, S.; Qi, T.; Huang, H.; Ren, Q.; Wu, D.; Chang, C.; Peng, W.; Liu, Y.; Peng, J.; Xie, D. The jasmonate-ZIM domain proteins interact with the R2R3-MYB transcription factors MYB21 and MYB24 to affect jasmonate-regulated stamen development in Arabidopsis. Plant Cell 2011, 23, 1000-1013. [CrossRef]

170. Rushton, P.J.; Somssich, I.E.; Ringler, P.; Shen, Q.J. WRKY transcription factors. Trends Plant Sci. 2010, 15, 247-258. [CrossRef]

171. Ramamoorthy, R.; Jiang, S.-Y.; Kumar, N.; Venkatesh, P.N.; Ramachandran, S. A comprehensive transcriptional profiling of the WRKY gene family in rice under various abiotic and phytohormone treatments. Plant Cell Physiol. 2008, 49, 865-879. [CrossRef]

172. Schmutz, J.; Cannon, S.B.; Schlueter, J.; Ma, J.; Mitros, T.; Nelson, W.; Hyten, D.L.; Song, Q.; Thelen, J.J.; Cheng, J. Genome sequence of the palaeopolyploid soybean. Nature 2010, 463, 178-183. [CrossRef]

173. Li, S.; Fu, Q.; Chen, L.; Huang, W.; Yu, D. Arabidopsis thaliana WRKY25, WRKY26, and WRKY33 coordinate induction of plant thermotolerance. Planta 2011, 233, 1237-1252. [CrossRef]

174. Li, S.; Zhou, X.; Chen, L.; Huang, W.; Yu, D. Functional characterization of Arabidopsis thaliana WRKY39 in heat stress. Mol. Cells 2010, 29, 475-483. [CrossRef]

175. Ding, Z.J.; Yan, J.Y.; Li, C.X.; Li, G.X.; Wu, Y.R.; Zheng, S.J. Transcription factor WRKY46 modulates the development of Arabidopsis lateral roots in osmotic/salt stress conditions via regulation of ABA signaling and auxin homeostasis. Plant J. 2015, 84, 56-69. [CrossRef] 
176. Zhou, X.; Jiang, Y.; Yu, D. WRKY22 transcription factor mediates dark-induced leaf senescence in Arabidopsis. Mol. Cells 2011, 31, 303-313. [CrossRef]

177. Ren, X.; Chen, Z.; Liu, Y.; Zhang, H.; Zhang, M.; Liu, Q.; Hong, X.; Zhu, J.K.; Gong, Z. ABO3, a WRKY transcription factor, mediates plant responses to abscisic acid and drought tolerance in Arabidopsis. Plant $J$. 2010, 63, 417-429. [CrossRef]

178. Shang, Y.; Yan, L.; Liu, Z.-Q.; Cao, Z.; Mei, C.; Xin, Q.; Wu, F.-Q.; Wang, X.-F.; Du, S.-Y.; Jiang, T. The Mg-chelatase $\mathrm{H}$ subunit of Arabidopsis antagonizes a group of WRKY transcription repressors to relieve ABA-responsive genes of inhibition. Plant Cell 2010, 22, 1909-1935. [CrossRef]

179. Yan, H.; Jia, H.; Chen, X.; Hao, L.; An, H.; Guo, X. The cotton WRKY transcription factor GhWRKY17 functions in drought and salt stress in transgenic Nicotiana benthamiana through ABA signaling and the modulation of reactive oxygen species production. Plant Cell Physiol. 2014, 55, 2060-2076. [CrossRef]

180. Wu, X.; Shiroto, Y.; Kishitani, S.; Ito, Y.; Toriyama, K. Enhanced heat and drought tolerance in transgenic rice seedlings overexpressing OsWRKY11 under the control of HSP101 promoter. Plant Cell Rep. 2009, 28, 21-30. [CrossRef]

181. Qiu, Y.; Yu, D. Over-expression of the stress-induced OsWRKY45 enhances disease resistance and drought tolerance in Arabidopsis. Environ. Exp. Bot. 2009, 65, 35-47. [CrossRef]

182. He, G.-H.; Xu, J.-Y.; Wang, Y.-X.; Liu, J.-M.; Li, P.-S.; Chen, M.; Ma, Y.-Z.; Xu, Z.-S. Drought-responsive WRKY transcription factor genes TaWRKY1 and TaWRKY33 from wheat confer drought and/or heat resistance in Arabidopsis. BMC Plant Biol. 2016, 16, 116. [CrossRef]

183. Peleg, Z.; Blumwald, E. Hormone balance and abiotic stress tolerance in crop plants. Curr. Opin. Plant Biol. 2011, 14, 290-295. [CrossRef]

184. Wani, S.H.; Kumar, V.; Shriram, V.; Sah, S.K. Phytohormones and their metabolic engineering for abiotic stress tolerance in crop plants. Crop J. 2016, 4, 162-176. [CrossRef]

185. Ryu, H.; Cho, Y.-G. Plant hormones in salt stress tolerance. J. Plant Biol. 2015, 58, 147-155. [CrossRef]

186. Rademacher, W. Plant growth regulators: Backgrounds and uses in plant production. J. Plant Growth Regul. 2015, 34, 845-872. [CrossRef]

187. Sun, Y.; He, Y.; Irfan, A.R.; Liu, X.; Yu, Q.; Zhang, Q.; Yang, D. Exogenous Brassinolide Enhances the Growth and Cold Resistance of Maize (Zea mays L.) Seedlings under Chilling Stress. Agronomy 2020, 10, 488. [CrossRef]

188. Islam, F.; Farooq, M.A.; Gill, R.A.; Wang, J.; Yang, C.; Ali, B.; Wang, G.-X.; Zhou, W. 2, 4-D attenuates salinity-induced toxicity by mediating anatomical changes, antioxidant capacity and cation transporters in the roots of rice cultivars. Sci. Rep. 2017, 7, 1-23. [CrossRef]

189. Hamayun, M.; Hussain, A.; Khan, S.A.; Irshad, M.; Khan, A.L.; Waqas, M.; Shahzad, R.; Iqbal, A.; Ullah, N.; Rehman, G. Kinetin modulates physio-hormonal attributes and isoflavone contents of soybean grown under salinity stress. Front. Plant Sci. 2015, 6, 377. [CrossRef]

190. Kaya, C.; Tuna, A.L.; Alfredo, A.A. Gibberellic acid improves water deficit tolerance in maize plants. Acta Physiol. Plant. 2006, 28, 331-337. [CrossRef]

191. Zhang, N.; Han, L.; Xu, L.; Zhang, X. Ethephon seed treatment impacts on drought tolerance of kentucky bluegrass seedlings. HortTechnology 2018, 28, 319-326. [CrossRef]

192. Bajwa, A.A.; Farooq, M.; Nawaz, A. Seed priming with sorghum extracts and benzyl aminopurine improves the tolerance against salt stress in wheat (Triticum aestivum L.). Physiol. Mol. Biol. Plants 2018, 24, 239-249. [CrossRef]

193. Xing, X.-H.; Fang, C.-W.; Long, L.; Jiang, H.-Q.; Qin, Z.; Jiang, H.-D.; Wang, S.-H. Improved drought tolerance by $\alpha$-naphthaleneacetic acid-induced ROS accumulation in two soybean cultivars. J. Integr. Agric. 2016, 15, 1770-1784. [CrossRef]

194. González, F.G.; Rigalli, N.; Miranda, P.V.; Romagnoli, M.; Ribichich, K.F.; Trucco, F.; Portapila, M.; Otegui, M.E.; Chan, R.L. An Interdisciplinary Approach to Study the Performance of Second-generation Genetically Modified Crops in Field Trials: A Case Study with Soybean and Wheat Carrying the Sunflower HaHB4 Transcription Factor. Front. Plant Sci. 2020, 11, 178. [CrossRef]

195. González, F.G.; Capella, M.; Ribichich, K.F.; Curín, F.; Giacomelli, J.I.; Ayala, F.; Watson, G.; Otegui, M.E.; Chan, R.L. Field-grown transgenic wheat expressing the sunflower gene HaHB4 significantly outyields the wild type. J. Exp. Bot. 2019, 70, 1669-1681. [CrossRef] 
196. Jin, Y.-M.; Piao, R.; Yan, Y.-F.; Chen, M.; Wang, L.; He,H.; Liu, X.; Gao, X.-A.; Jiang, W.; Lin, X.-F. Overexpression of a new zinc finger protein transcription factor OsCTZFP8 improves cold tolerance in rice. Int. J. Genom. 2018. [CrossRef]

197. Han, G.; Lu, C.; Guo, J.; Qiao, Z.; Sui, N.; Qiu, N.; Wang, B. C2H2 zinc finger proteins: Master regulators of abiotic stress responses in plants. Front. Plant Sci. 2020, 11, 115. [CrossRef] 